\title{
Article \\ Smart Clothing Framework for Health Monitoring Applications
}

\author{
Mominul Ahsan ${ }^{1, *(\mathbb{D}}$, Siew Hon Teay ${ }^{2}$, Abu Sadat Muhammad Sayem ${ }^{3}{ }^{(1)}$ and Alhussein Albarbar ${ }^{4}(\mathbb{C}$ \\ 1 Department of Computer Science, University of York, Deramore Lane, York YO10 5GH, UK \\ 2 Diagnostic Solutions Limited, Unit 4C Rossett Business Village, Rossett Nr Chester LL12 0AY, UK; \\ shteay@diagsol.co.uk \\ 3 Manchester Fashion Institute, Manchester Metropolitan University, Manchester M15 6BG, UK; \\ asm.sayem@mmu.ac.uk \\ 4 Department of Engineering, Manchester Metropolitan University, John Dalton Building, Chester Street, \\ Manchester M1 5GD, UK; a.albarbar@mmu.ac.uk \\ * Correspondence: md.ahsan2@mail.dcu.ie
}

Citation: Ahsan, M.; Teay, S.H.; Sayem, A.S.M.; Albarbar, A. Smart Clothing Framework for Health Monitoring Applications. Signals 2022, 3, 113-145. https://doi.org/ $10.3390 /$ signals3010009

Academic Editor: Chin-Ling Chen

Received: 30 November 2021

Accepted: 21 February 2022

Published: 2 March 2022

Publisher's Note: MDPI stays neutral with regard to jurisdictional claims in published maps and institutional affiliations.

Copyright: (c) 2022 by the authors. Licensee MDPI, Basel, Switzerland. This article is an open access article distributed under the terms and conditions of the Creative Commons Attribution (CC BY) license (https:/ / creativecommons.org/licenses/by/ $4.0 /)$.

\begin{abstract}
Wearable technologies are making a significant impact on people's way of living thanks to the advancements in mobile communication, internet of things (IoT), big data and artificial intelligence. Conventional wearable technologies present many challenges for the continuous monitoring of human health conditions due to their lack of flexibility and bulkiness in size. Recent development in e-textiles and the smart integration of miniature electronic devices into textiles have led to the emergence of smart clothing systems for remote health monitoring. A novel comprehensive framework of smart clothing systems for health monitoring is proposed in this paper. This framework provides design specifications, suitable sensors and textile materials for smart clothing (e.g., leggings) development. In addition, the proposed framework identifies techniques for empowering the seamless integration of sensors into textiles and suggests a development strategy for health diagnosis and prognosis through data collection, data processing and decision making. The conceptual technical specification of smart clothing is also formulated and presented. The detailed development of this framework is presented in this paper with selected examples. The key challenges in popularizing smart clothing and opportunities of future development in diverse application areas such as healthcare, sports and athletics and fashion are discussed.
\end{abstract}

Keywords: wearable technology; smart clothing; sensor and textile materials; data communication and analysis; artificial intelligence; decision making

\section{Introduction}

Smart wearables, such as fitness bands and smart watches, and sensor-integrated smart clothing are gaining fast popularity, particularly in the sectors of fitness, personalized healthcare and sports. However, the ergonomic issues with their frequent donning and doffing within short intervals are deemed an extra burden for the users, especially the elderly, infants and young children. The prevailing wearable devices suffer from a poor ergonomic design and thus fail to cover the human body efficiently to ensure uninterrupted and noise-free data gathering as well as to provide the expected level of wearer comfort when used on a long-term basis [1].

However, the popularity of wearable technologies has instigated the rapid growth of smart clothing [2]. The idea of smart clothing is based on the integration of wearable microelectronic technologies in clothes, such as coats, pants, shirts and leggings, which cover a major part of the human body, wrapping around the wearer in order to monitor their health conditions for identifying the need for a clinical intervention and/or improving physical fitness. Such products are already becoming available on the market, for example, smart shirts from Hexoskin, Athos, OM signal, etc.; compression sleeves from Komodotec; leggings from Wearable X; and so on [2-8]. It is expected that they must be flexible, foldable, washable, self-cleanable, breathable and stretchable in order to be worn for longer periods. 
The market for smart clothing is estimated to reach a value of USD 8.8 billion by 2024 . The demand for smart clothes is growing rapidly in many industries, from retail to military and sports to healthcare [3].

Ongoing research efforts are focusing either on developing smart clothes or monitoring and analysing health for decision-support systems. However, there is still a lack of a comprehensive framework that can combine both the smart clothes development part and decision-making part. This work proposes a novel smart clothes framework, suggesting the best textile and sensor materials for monitoring and analysing diverse health-related parameters using modern technologies (AI, machine learning and edge computing) to make appropriate decisions for enhancing the quality of human life, principally that of elderly people, athletes and sportsmen.

The aim of this work is to develop a comprehensive and complete smart clothes framework, combining both the smart clothes development side and data analytics side to monitor health conditions accurately. The following contributions have been made in this work:

(a) Identify potential textile and sensors materials for smart clothes design requirements;

(b) Identify suitable sensing mechanisms;

(c) Investigate state-of-the-art sensor integration techniques;

(d) Suggest appropriate techniques for data collection and analysing with a smartphone and IoT-based cloud system;

(e) Suggest advanced data analytics with AI techniques to make decisions for healthcare.

This paper is organized as follows: Key points on wearable technology and information on smart clothing, including application areas, categories, advantages and current advancements, are presented in Section 2. A novel framework for developing smart clothing (e.g., leggings) with conceptual design specifications, selection criteria of suitable sensor and textile materials with their integration techniques is provided in Section 3. Data collection from smart clothing, data processing and decision making are also presented within the framework. The overall challenges of health monitoring using smart clothing in terms of sensor integration with textiles (fibre, yarn and fabric) and data communication technology are reported in Section 4. Finally, conclusions are drawn in Section 5.

\section{Wearable Technology and Smart Clothing}

This section presents the most popular wearable technologies that are currently used for health monitoring purposes. The types of biosignals measured in the human body for monitoring health using the smart clothing are also given. Furthermore, this section also presents the advantages and advancement of smart clothing through a rigorous literature review, a comparison between the traditional wearable system and smart clothing and discussions on the wireless communication, antenna design, state-of-the-art AI, machine learning, deep learning, and edge computing of wearable technology. Finally, the limitations of the existing works are critically analysed and discussed.

\subsection{Wearable Technology}

Wearable technology comprises the electronic devices that can be attached to the human body for monitoring and delivering intelligent services. Several types of wearable technologies, including smart watches, smart jewellery, fitness trackers, smart shoes, smart belt, brain activity tracker, etc., are currently used for the monitoring of different body parameters (Figure 1).

Wearable technologies were classified into four different categories, including accessory, textile or fabric, patchable and implantable wearables, by the International Electrotechnical Commission (IEC) [4]. The focus of this paper is on textile-based wearable technology or smart clothing, as shown in Figure 2. Interested readers are advised to consult the recent papers published on wearable technologies [5-7]. 




Figure 1. Examples of wearable technology.

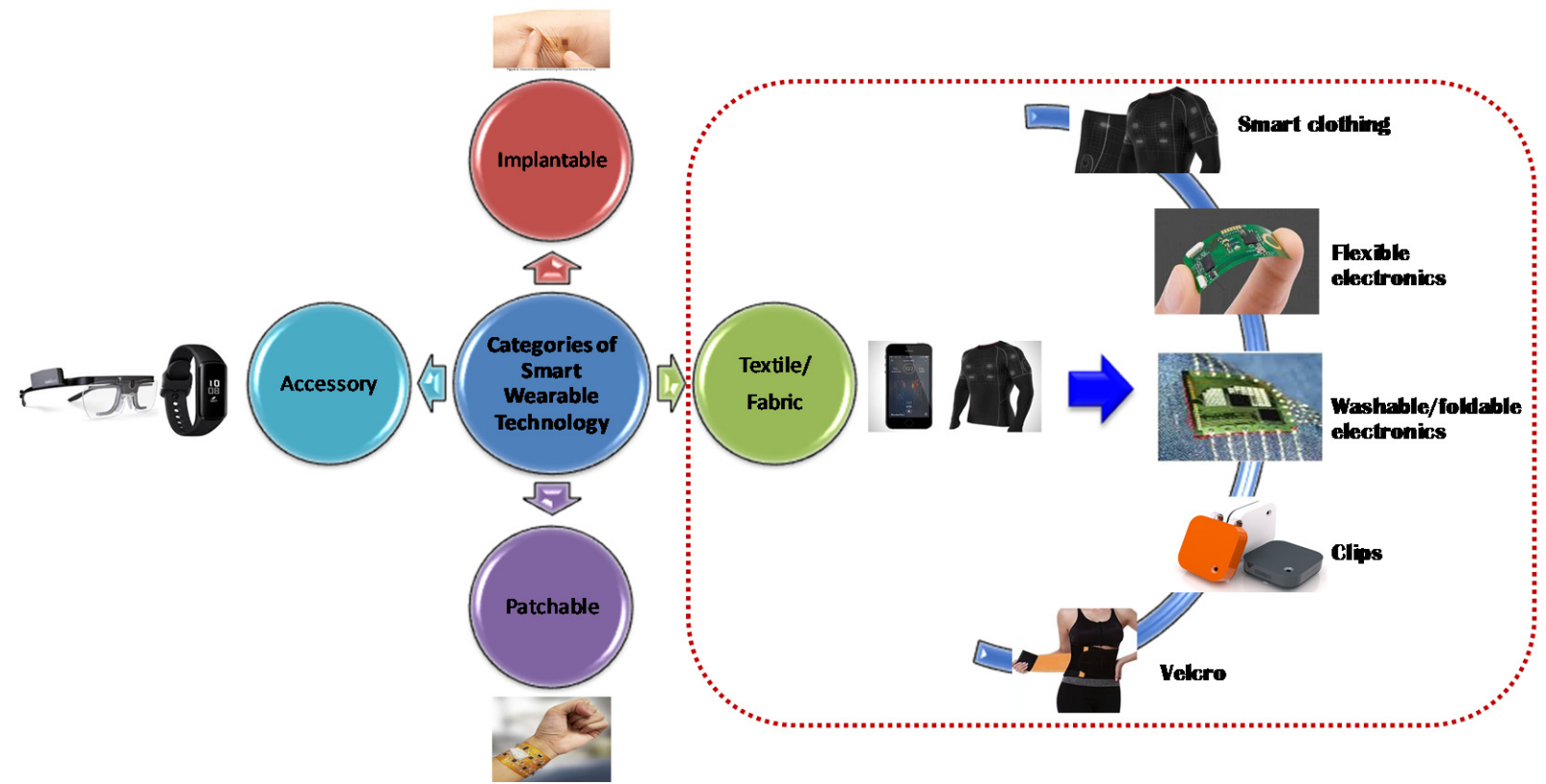

Figure 2. Categories of wearable technology.

\subsection{Smart Clothing}

Smart textiles are developed by embedding wearable technologies into fibre, yarn, fabric or garments. People know these as e-textiles, smart garments or electronic textiles. The clothing is created to match everyday style and is updated over time. A strong interface between the real world and the digital world is created through smart clothing with the use 
of smartphones and other devices. Furthermore, clothes are suitable for this purpose since the early stages of textile and flexible electronics can adapt to the direct contact with one's body through clothes [7]. Smart clothing is more natural to wear compared to the other wearables and covers a wider area for monitoring. Biological events including heartbeat, muscle contractions, etc., are sources of various biosignals [8]. Biosignals generated from human body are categorized as shown in Figure 3.



Figure 3. Types of biosignals in the human body (information taken from [8]).

Smart clothing is the next generation of clothes, with potential functionality in tracking individual's biometrics, responding to environmental changes, etc. The advantages of wearing smart clothing are presented in Figure 4. Therefore, the focus is shifted to developing smart clothes instead of concentrating only on smart watches and smart bands.

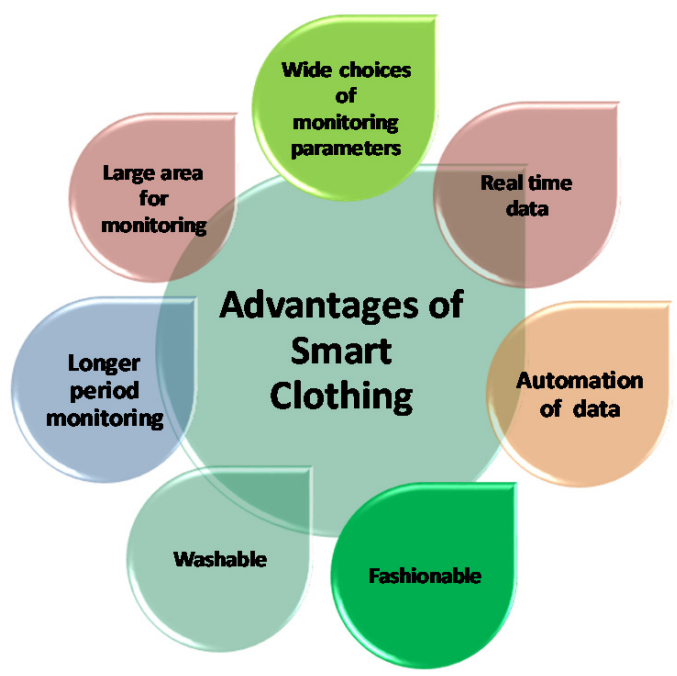

Figure 4. Advantages of smart clothing.

Wearable 2.0 is proposed in [9] as smart clothing by incorporating multiple connected devices, which can communicate with cloud-based services to offer an improved lifestyle. Smart clothing can ensure comfort, usability, accuracy, product washability, and support for real-time monitoring. Figure 5 presents a comparison between a conventional wearable system and smart clothing. 


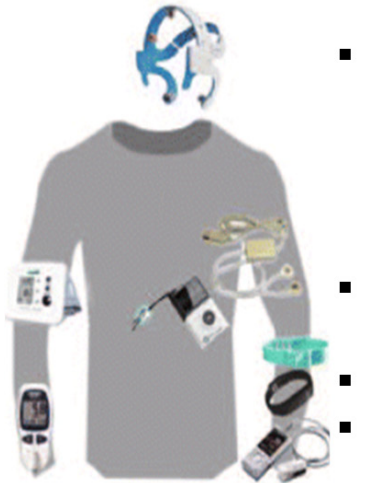

Wearable 1
- Product: smart bracelet, smart watch, ECG and heart rate monitoring device, fall detection device

- Comfort Index: lowhigh

Usability: easy-hard Machine wash: no



Wearable 2
- Product: smart socks, smart bra, smart leggings, smart T-shirt

- Comfort Index: high

- Usability: very easy

- Machine wash: yes

Figure 5. Comparison between traditional wearable system and smart clothing (adapted from [9]).

As this paper focuses on the development of a smart leggings framework, a schematic diagram of smart leggings and other fabric-based accessories for the hip, thigh, knee, ankle and foot is presented in Figure 6.

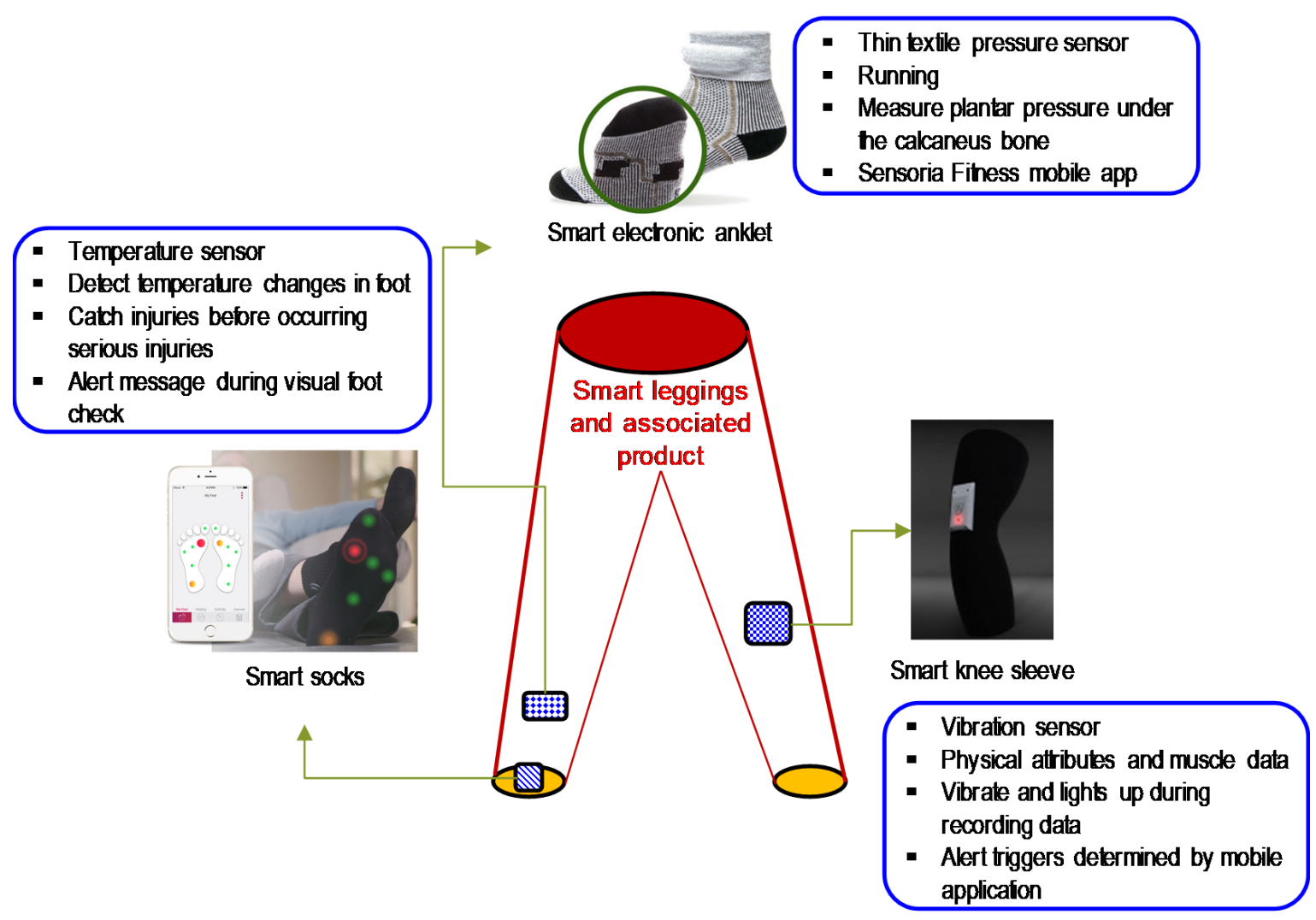

Figure 6. Smart leggings and associated products.

\subsection{Advancement in Smart Clothing}

The concept of Internet-of-Smart-Clothing can handle societal challenges while reducing the rising financial load of healthcare services. Physiological monitoring with smart clothing has the potential to diagnose health problems at an early stage, moving away from the traditional treatment approach to a disease prevention approach. Table 1 presents a summary of the current development of smart clothing in various sectors, including smart health, vulnerable groups (monitoring of babies and the elderly), sports and wellness, industry, defence and public safety, and interaction with the environment. 
Table 1. Examples of the current development of smart clothing in categories

\begin{tabular}{|c|c|c|c|c|}
\hline Category & Name of Technology & Sensor Used/Signals & Monitoring Parameter & Ref \\
\hline \multirow{9}{*}{ Smart Health } & smart clothing & $\begin{array}{c}\text { electrocardiogram (ECG), electromyogram (EMG), } \\
\text { electroencephalography (EEG) }\end{array}$ & $\begin{array}{c}\text { physical stress levels, breathing patterns, sweat, temperature, } \\
\text { energy, burnt rate }\end{array}$ & [10] \\
\hline & internet-of-smart-clothing & ECG signals & sleep disorders & [11] \\
\hline & T-shirt & ECG signals & heart rate & [12] \\
\hline & a smart clothing prototype & ECG monitoring & human respiration & [13] \\
\hline & a smart garment & ECGs & respiration rate & [14] \\
\hline & Smart Garment & triaxle accelerometer and gyroscope & rehabilitation for assisting osteoarthritis $(\mathrm{OA})$ patients & [15] \\
\hline & a Bluetooth-enabled smart garment & acromion sensor & rehabilitating shoulders & [16] \\
\hline & vivo metrics life Shirt & accelerometers & pulmonary, cardiac, and other vital signs measurement & [17] \\
\hline & sensatex smartShirt & ECG & respiration rate and blood pressure & [18] \\
\hline \multirow{5}{*}{$\begin{array}{l}\text { Baby and Elderly } \\
\text { Monitoring }\end{array}$} & a smart garment & ECG signal, textile electrode & new-born monitoring & [19] \\
\hline & baby vest & $\begin{array}{l}\text { respiratory sensors, electrodes for ECG, moisture } \\
\text { and temperature sensors }\end{array}$ & $\begin{array}{l}\text { respiration, heart rate, temperature and humidity, } \\
\text { excessive sweating }\end{array}$ & [20] \\
\hline & wearable textile & magnetic reed sensors & accident prevention for babies in crawl phase & [21] \\
\hline & baby night watch & ECG, 3D accelerometer, inertial sensor & $\begin{array}{l}\text { infant's body temperature, heart and breathing rates and } \\
\text { body position }\end{array}$ & {$[22]$} \\
\hline & $\begin{array}{l}\text { T-shirt } \\
\text { garment for older walkers }\end{array}$ & $\begin{array}{l}\text { knitted sensor } \\
\text { shimmer sensor (ECG and accelerometer data) }\end{array}$ & $\begin{array}{l}\text { heart attack or a stroke for elderly people } \\
\text { user's heart rate }\end{array}$ & $\begin{array}{l}{[23]} \\
{[24]}\end{array}$ \\
\hline \multirow{6}{*}{ Sports and Wellness } & smart shirt & body-worn inertial sensors (acceleration sensors) & monitoring posture & [25] \\
\hline & wearable Instrumented vest & accelerometer sensor & monitoring elderly people's postures & [26] \\
\hline & a smart t-shirt & physiological, ambient and motion sensors & detection of inactive lifestyle using machine learning & [28] \\
\hline & a wearable device & accelerometer & acknowledgement of food intake and physical activity & [29] \\
\hline & a smart sock & Lilypad Arduino & heart rate, heart rate variation, oxygen saturation, temperature & [30] \\
\hline & smart clothing & electrocardiograph signals & physical indicator monitoring & [31] \\
\hline \multirow{5}{*}{$\begin{array}{l}\text { Industry, Defense } \\
\text { and Public Safety }\end{array}$} & a smart vest & ECG, Thoracic Electrical Bio-impedance & $\begin{array}{l}\text { musculoskeletal disorders and cardiovascular diseases } \\
\text { thermal work limits, alertness and fitness for duty status, }\end{array}$ & [32] \\
\hline & wearable computers and smart clothing & textrodes, motion sensors & musculoskeletal fatigue limits, neuropsychological and & {$[33,34]$} \\
\hline & a smart slim fit T-shirt & accelerometer sensor, ECG & $\begin{array}{l}\text { physiological conditions } \\
\text { heart rate, heart rate variability (HRV) }\end{array}$ & [35] \\
\hline & a firefighting garment & $\begin{array}{l}\text { temperature sensor, heart-beat sensor, } \\
\text { accelerometer sensor }\end{array}$ & heart rate, activity, body temperature & {$[36]$} \\
\hline & $\begin{array}{l}\text { a smart T-shirt, a jacket and a pair of } \\
\text { boots }\end{array}$ & textile motion sensor, $\mathrm{CO}$ sensor & $\begin{array}{l}\text { heart and breathing rates, body temperature, blood oxygen } \\
\text { saturation, position, activity, and posture }\end{array}$ & [37] \\
\hline \multirow{3}{*}{$\begin{array}{l}\text { Interaction with } \\
\text { Environment }\end{array}$} & a smart wristband & $\begin{array}{l}\text { a 3-axis accelerometer (ADXL335), Lilypad } \\
\text { Arduino based microcontroller }\end{array}$ & gesture processing to control lights & [38] \\
\hline & interactive clothes & NFC tags and IOT & $\begin{array}{l}\text { to identify cheap replicas, track loyal customers, minimize the } \\
\text { wastage of resources track of the goods using }\end{array}$ & [39] \\
\hline & intelligent T-shirt & accelerometers Lilypad and 3D accelerometer & heart rate & [40] \\
\hline
\end{tabular}




\subsection{Antenna Design for Smart Cloth}

Research on body-centric wireless communication is rapidly increasing day by day. As an example, smart clothing is a wearable personal communication system that is used for various applications including eldercare, medical emergencies, firefighting, military applications, and athlete monitoring. Three types of textile antennas have been designed, including a patch antenna, slot antenna, and planar inverted-F antenna (PIFA), with all being operated at $2.45 \mathrm{GHz}$ WLAN band for smart clothing applications [41].

Conventional antennas are manufactured by printed circuit boards (PCBs), which are uncomfortable to use for human body and are not washable. Limited design space for the antennas of portable devices may enforce performance restrictions. Flexible antennas are made up of two main parts which are a conductor (copper, aluminium, silver, etc.) and a dielectric (polymers, paper, foam, plastics, textile fabrics and soft PCB). A conductive material is utilized as a radiating component whereas a dielectric material behaves as the substrate that helps the radiating component.

Textile antennas with metalized fabric including Flectron, Shieldex, REMP, and Shintron can raise comfort and make the clothing washable [42]. Therefore, the antenna design is a major concern for smart clothing where key factors including material selection, fabrication methods and analysis should be considered. A circular patch antenna and rectangular patch antennas made of taffeta and polyester are used for the operation in the WLAN band. An Inverted-F antenna (PIFA)-type textile antenna is useful for increasing bandwidth and preventing frequency shifts while it is used in the human body. A UWB wearable antenna was constructed with the use of liquid crystal polymer substrates, showing enhanced performance in terms of return loss and radiation pattern for various conditions including folding, heating and wetting. A dual-band button antenna was designed for use at 2.4 and $5 \mathrm{GHz}$. The pattern of radiation for this antenna is similar to monopole antennas.

It was observed in the literature that flexible substrates that have high moisture stability and bending capabilities are beneficial in the design of wearable antennas. However, some challenges and limitations should be considered in designing flexible antennas, including substrate thickness, the dimensions of the antenna, feeding techniques, the physical properties of materials and frequency range [43]. The design of a wearable singlelayer antenna becomes possible and we can also determine which properties of these antennas are influenced by the human body at the time the body tissue is subjected to antenna radiation and identify the resistance parameters. [44].

\subsection{Wireless Communication}

Several technologies are integrated with smart clothing as the medium of wireless communication. These include 3G/4G/5G, ultrasounds, infrared, ZigBee, Long-Range Wide Area Network (LoRa WAN), Ultra-Wide Band (UWB), Wireless HART, SigFox, ANT+, Weightless-P, Wi-SUN and IEEE 802.11ah [7]. Data transmission is performed with the use of both a source and storage centre, including a computer or cloud system communicating with Central Processing Units (CPUs), microcontrollers, Field-Programmable Gate Arrays (FPGAs), or System-on-Chips (SOCs). Information is exchanged by a communications gateway with smart clothing through cloud servers or a block chain [45]. Wireless data communication is performed through a Body Area Network (BAN), which distributes information from electronic sensors embedded into smart clothes. Then, data from smart clothing are collected by a Local Area Network (LAN), sent via a cloud-based server. A mesh wireless network is responsible for communicating with each object and machine that are connected around the setup. The Wide Area Network (WAN) is responsible for many aspects of the technology, such as internet connection [46]. A summary of current wireless technologies mostly used for developing smart clothing is provided in Figure 7. 


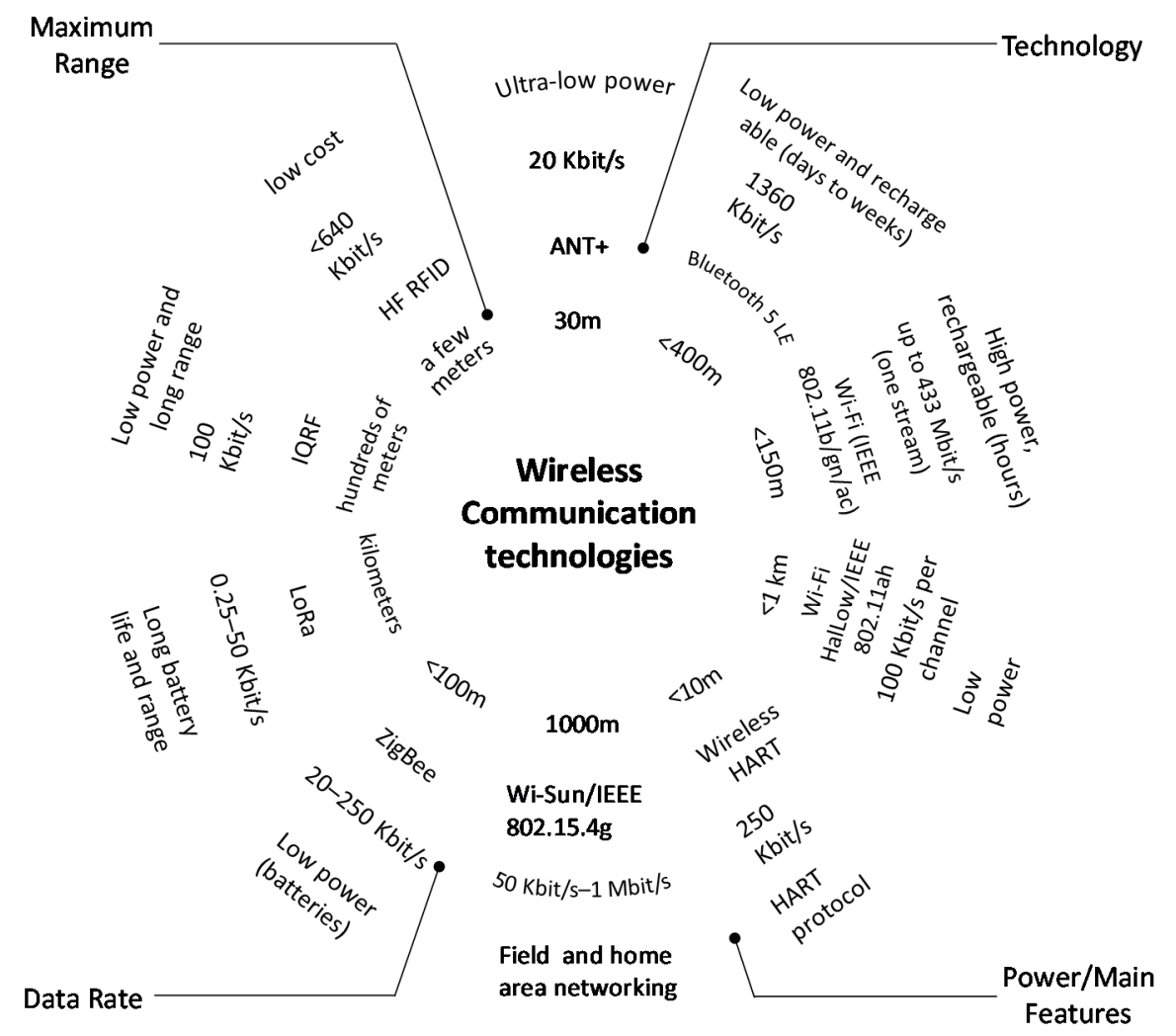

Figure 7. Summary of wireless communications technologies for smart clothing (information from [46]).

\subsection{Computational Approach on Wearable Technologies}

\subsubsection{Sensor-Based Technology}

Current advances in low-power electronics and the miniaturization of sensors have paved the route for a wide range of wearable devices for the applications of monitoring health and fitness. Huge research and commercialization endeavours all over the world are concentrated on developing wearable biosensors that can randomly monitor biochemical markers in the human body for managing diseases diagnosis, prognosis, and monitoring of fitness [47], particularly for people in North America.

Talkhooncheh et al. [48] have proposed an efficient cold-starting biofuel-cell-based energy harvester system, fabricated in $65 \mathrm{~nm}$ CMOS, which can perform a cold start-up with a low voltage $(0.39 \mathrm{~V})$ by employing a start-up enhancement block where a power efficiency of $86 \%$ is achieved. The outcome of this research is that the energy harvester chip can attain an enhanced efficiency with below $0.4 \mathrm{~V}$ of input voltage and $5.5 \mu \mathrm{W}$ of average output power. However, the authors have not presented how to control oscillation failure at the lower supplies.

A review on wearable electrochemical biosensors was conducted by Min et al. [47]. The authors have presented the current advancement and commercialization of wearable electrochemical sensors for measuring blood glucose levels to monitor dehydration in fitness applications. Although the authors have shown great prospects on wearable electrochemical sensors for both remote and personalized healthcare, they have not provided the recent advancements in and future of smart clothing.

Gao et al. [49] presented research work on flexible and fully integrated wearable biosensors for measuring glucose, lactate, sodium and potassium ions, and skin temperature. The signals are processed through a system interfacing with the skin with silicon integrated circuits merged on a flexible circuit board. The system is capable of measuring the detailed sweat profile of humans while they are doing both indoor and outdoor physical activities. The system is also capable of performing a real-time assessment of the physiological state through a mobile app connecting with cloud services. Although the system can be applied 
in physiological monitoring applications, information on introducing smart clothing and a comprehensive framework for developing the smart clothing is not given.

Gao et al. [50] summarized the current advancements of skin-interfaced wearable sensors. The authors introduced the strategies of materials selection and structure design, which can enable the sensors to contact human skin. The authors have also classified and discussed physical and biochemical sensors. In addition, power issues, wireless communication and how to analyse the data are also discussed in their paper. Challenges and further opportunities are also identified by the authors for future wearable devices and systems. Although the paper has reviewed many key parts on wearable technology, a complete framework for developing smart clothing is missing.

A microfluidic tactile diaphragm pressure sensor based on embedded Galinstan microchannels has been developed by Gao et al. [51]. An embedded equivalent Wheatstone bridge circuit was used to take advantage of tangential and radial strain fields, where the sensitivities obtained were as high as $0.0835 \mathrm{kPa}^{-1}$ with superior response linearity. The bridge circuit provides built-in temperature compensation at temperatures of 20 and $50{ }^{\circ} \mathrm{C}$ without external offsets. According to the authors, the liquid-state diaphragm pressure sensors may be useful for monitoring pressure in various electronic skin and smart textile applications. However, a complete smart clothing framework has not been offered.

\subsubsection{Edge Computing for Health Monitoring}

The viability and acceptance of mobile healthcare are currently increasing. The upcoming fifth generation (5G) wireless systems appear to sustain exceptional high capacity, low latency, and massive connectivity [52]. The ongoing rapid advancement of wireless communication, data processing, IoT, the cloud, and edge computing have made mobile healthcare easier to implement than it was in the past [53]. Wireless Body Area Networks (WBAN) as part of IoT offer real-time and continuous healthcare monitoring to improve quality of life [54]. More recently the edge computing paradigm has fascinated researchers as a legitimate replacement of the standard cloud-based systems to reduce interaction timing and gather a huge amount of real data from IoT devices. Edge-based approaches can support time-dependent applications in the Industry 4.0 context in the near future [55].

Yang et al. [56] proposed a novel offloading framework for multiserver multiaccess edge computing (MEC) network. In their proposed network, each access point (AP) is outfitted with an MEC server (MES) supporting mobile users (MUs) in executing computationintensive tasks through offloading. The offloading decision problem was presented as a multiclass classification problem and the MES computational resource allocation task was expressed as a regression problem. A feedforward neural network (MTFNN) model was developed and trained to optimize the offloading decision and computational resource allocation as a mixed-integer nonlinear programming problem (MINLP) with high accuracy by solving the optimization problem. Then, the pretrained model directly extrapolated the solution to the MINLP problem online with very low computational cost. The testing results proved that the proposed MTFNN model outperforms the traditional optimization algorithms in terms of inference accuracy and high computational time. However, the authors could have provided some suggestions for generating the training datasets more efficiently.

A novel framework for developing IOT with mobile edge computing (MEC)-based hierarchical machine learning (ML) task distribution for industrial applications was proposed by Yang et al. [57]. ML and deep ML models developed for their device and MES, respectively, were pretrained offline using historical data and deployed accordingly to improve the computational execution time for the MEC setting. A joint optimization problem was devised to reduce the total delay considering a few factors including the ML model complexity and inference error rate, data quality and communications bandwidth A closed-form solution was developed, and an optimal offloading strategy selection algorithm was proposed for multiple devices. The results showed that the communication cost progressively turns into a bottleneck, which reduces the delay of performing computing 
tasks using the edge computing strategy. However, the authors could exploit more AI techniques to verify the capability of the proposed framework.

Fog and mobile edge computing have important roles in solving some difficulties of cloud computing, including mobility, response time, and location perception. A healthcare framework was proposed to detect and observe type 2 diabetes patients using a novel IoT system-based decision-making model. A hybrid technique based on both type 2 neutrosophic and Višekriterijumsko kompromisno rangiranje (VIKOR) methods was applied. The results achieved by the proposed work showed the validity and robustness through reducing the execution time by $9.8 \%$ and increasing the patients' survival rates using personal data and symptoms [58]. However, the authors could investigate advanced machine learning methods to enhance the prediction accuracy.

Yang et al [59] proposed an emotion-aware system embedding a personal robot, smart clothing, and edge cloud for interacting with users. The EEG data, audio/video data, touch data, and physiological signals of the user were collected using smart clothing. Design emotion perception and interaction algorithms such as intelligent recommendation, relation recognition and emotional expression recognition were designed through the use of artificial intelligence and a knowledge graph. A testbed was also developed to conduct different tests for checking the performance of the proposed emotion-aware system. The results showed that the system is efficient in terms of improving people's mental health.

An ECC-based smart healthcare system was proposed using an edge cognitive computing and data-driven approach by Chen et al. [60]. The system monitors and analyses physical health-related data from the users using cognitive computing. The experimental results showed that the proposed system has superior user data cognition and resource cognition, a high energy efficiency, low cost, and high user Quality of Experience (QoE) in an emergency case and reasonably improved survival rates. However, the authors could build an emotional recognition system by combining this with the current system for carrying out corresponding care.

\subsubsection{Machine Learning for Healthcare}

Machine learning (ML) is highly prevalent, especially for analysing health-related data in the case of making decisions by reducing the dimensionality of data to make it manageable. Firstly, feature extraction is a vital job for extracting and analysing signals, and is considered as the main feature for corresponding data. To process physiological signals such as ECG, Fourier Transform and Wavelet Transform are widely used [61].

ML techniques learn and communicate information from numerous sources and realize unseen relationships among the source factors [30]. Various popular ML algorithms including Neural networks (NN), Naïve Bayes, k nearest neighbour (k-NN), Support Vector Machine (SVM), Decision Tree (DT), regression, clustering, Hidden Markov model (HMM), Gaussian Mixture Modelling (GMM), etc., are currently used for analysing and predicting human health conditions to support decision making in both normal and emergency situations. Predictive models are built by these algorithms due to their outstanding training speed, excellent memory capability and great accuracy in predicting health conditions. $\mathrm{K}-\mathrm{NN}$ classifiers determine geometrical gaps between feature vectors from various classes. Their use is a straightforward, effective nonparametric method used for classification, regression, recognition, etc. [62]. SVM classifies data through a linear decision boundary to separate all data points in binary classes. In addition, Naive Bayes carries out data classification based on the uppermost probability of its belonging to individual classes. Neural networks can learn, recall and generalize the targeted data by adjusting weights to check and test models to predict the ultimate result [63]. Reinforcement learning works through trial and error when investigating data and improves outcomes mostly for people affected by chronic diseases [30].

Satinet and Fouss [64] have proposed supervised machine learning tools to generalize the findings of existing life cycle assessment studies (LCAs) and to develop an ML model for assessing the sustainability of clothing products easily and over their lifecycles with 
limited data. Nine various supervised machine learning algorithms were tested considering a five-fold cross validation. The average accuracy, weighted average, recall and precision, mean squared error (MSE), Kendall's Tau-b (Tau-b), and ordinal classification index (OCI) were considered as the key parameters for each algorithm. It was observed from the results that an average accuracy of 0.90 or higher was achieved by bagged decision trees and random forest algorithms. However, this work is dedicated to creating a classification model for a category of single product, but the model could be extended to other product categories and/or to other datasets.

A soft computing technique was applied to build a model that is capable of estimating the heart rate (HR) response to exercise of constant intensity and recovery [65]. Multilayer perceptron artificial neural networks (NN) were employed using raw heart rate time series data. The results showed a mean relative square error of the estimated HR values of the order of $10^{-4}$ with an absolute error as 1.19 beats per minute, which is low. The performance of the model proved that the NN model is capable of predicting the HR response to any persistent workout strength. However, the authors provided only the computational method to monitor heart rate rather than providing a design framework of wearable technology.

Foysal et al. [66] proposed "SmartFit", an interactive smartphone application which will recommend optimal fitting clothes by detecting the body shape of a consumer. The goal of this project was to solve clothing fitting issues, convenience and improve online garment shopping experiences for consumers. Image processing and machine learning (SVM, NN, KNN) were employed to analyse the smartphone images. Four body shapes, including inverted triangle, pear, hourglass, and rectangle, were classified with an accuracy of $87.50 \%$ on average. The proposed method is useful to increase the feasibility of online clothing shopping with optimally fitting garment suggestions being accurate and personalized, and as a result retailers can benefit from increased revenues. However, the method is not suitable to detect other body types.

\subsubsection{Deep Learning for Healthcare}

At present, deep learning has played a great role in analysing a huge amount of data with its advanced techniques. It acts through processing a large amount of data to solve complex problems using artificial neural networks. There are some basic differences between traditional machine learning and deep learning algorithms. Traditional machine learning algorithms learn from model functions and then predict future activity from history, whereas the deep learning ones contain more than one hidden layer to understand data features and relations among the parameters [67]. Deep learning has elevated performance in learning feature representation from raw data. Currently, many deep learning algorithms including Deep Neural Network (DNN), Convolutional Neural Networks (CNNs), Recurrent neural networks (RNN), Restricted Boltzmann machines and Deep autoencoders are available for the applications of handling large amount of data and making effective decisions [67].

Deep learning algorithms are principally self-directed, generating new features and recommending solving end-to-end problems, which can be applied in appropriate data analytics and decision making through the data collected by the smart clothing [68]. Namely, CNN performs enhanced extractions of data information compared to machine learning algorithms such as SVM. Furthermore, RNN is applied for analysing health-related temporal sequence data. Learning features and classification automatically with high accuracy and performing automatic feature extraction without the involvement of human intervention are the key advantages of deep learning. The key shortcomings of deep learning are that it is extremely time consuming and requires superior performances of the hardware. Deep learning has the capability of offering results for complicated analysis. For example, due to them having numerous levels of complexity, the networks perform complex decision making in many cases. However, this is expensive for training and building models in terms of time. 
Alhussein and Muhammad [53] suggested a convolutional neural network (CNN) with a transfer learning technique for detecting voice pathology in a mobile healthcare framework. The voices were obtained using a smartphone and processed. The experimental results showed that the accuracy of voice pathology detection was as high as $97.5 \%$. According to the achieved results, the cloud manager directs the decision and recording of the voice signal to the local caring authority. Then, the authority or doctor analyses the signal, makes the decision and gives advice to the patients. However, the authors could add GUI to make the outcome visible.

Hong et al. [69] recommended a method combining a hybrid recommendation algorithm and deep neural networks (DNN) for predicting disease considering medical records while ambiguous explanation of symptoms detected. The authors used real-world datasets for predicting potential phenotypes by analysing the high-level and low-level order features of the disease. The experimental results showed considerable accuracy in predicting diseases; however, further research is still required to investigate additional methods to enhance the capability of prediction accuracy and conditions for making appropriate decisions.

Turner and Hayes [70] proposed a method for classifying unnaturally induced gait alterations by merging noninvasive wearable sensors and deep learning. The proposed method diagnosed gait abnormalities considering a symptom that has could potentially indicate movement illnesses. For collecting pressure data on 12 patients, long-term and short-term memory networks with deep learning architectures were employed in their method. The experimental results showed a good accuracy of $82.0 \%$ in classifying the gait function of patients precisely, which can be beneficial in making decisions regarding the status of a patient. However, the system did not provide a performance comparison with other methods to understand the capability of the proposed method.

Although many research works are currently being conducted on wearable technology and smart clothing, a lot of technical challenges have also been observed in the state of the art. For example, there is a lack of control over oscillation failure at lower supplies in the sensors system of wearable technology [48]. Additionally, there is a shortage of information provided on developing smart clothing materials and a comprehensive framework combining both the development and decision making [50,51]. It can observed from the literature that there is a lack of advanced machine learning methods to enhance prediction accuracy through smart clothing [58]. Some AI tools are focused on classifying only a single product, which is not suitable for other product/data sets $[64,65]$. Some methods are suitable for detecting particular body types and unable to detect other body types [66]. Furthermore, a few AI models developed are expensive [68] and lack an integrating GUI for making the decision visible [53]. Some works justified their proposed method by investigating only one technique where a performance comparison is required by employing more than one technique to make the system valid $[69,70]$.

To overcome the above challenges, the authors of this paper developed a comprehensive and complete smart clothing framework for improving quality of life.

\section{Proposed Framework for Smart Clothing (Leggings)}

This section offers a proposed framework for developing smart clothing with a specific example of leggings for health and fitness monitoring. The framework shows in detail the development of the smart clothing and how it can be used for health-monitoring purposes. Application scenarios, design requirements, textile materials, and sensor materials, including their integration process, are described elaborately. In addition, the sensing mechanism, data collection (bio signals) and processing, data analysis and decision-making process for monitoring health securely are presented.

Current smart clothes are not free from shortcomings, such as potential discomfort from electronic hardware integrated with fabric, washability, durability and proneness to motion issues, resulting in a lack of accuracy in sensing and tracking human health condition and fitness. Several frameworks for smart clothing have been proposed in the 
literature to monitor and track health conditions. These frameworks focus on either smart clothing sensors and textile materials, mechanism and integration [2,71-73] or data collection techniques, analysis methods, cloud services and displaying the decision [32,36,74-76] separately. However, no integrated complete framework for smart clothing is available. In this paper, a framework has been proposed for developing smart leggings in Figure 8 by combining the design criteria, textile materials, sensor materials, sensor integration with textile and decision support system. Further details of the proposed framework are presented in the following sections.



Figure 8. A proposed framework for developing smart clothing (e.g., leggings) for health and fitness monitoring.

\subsection{Application Scenario}

Smart clothing by incorporating multiple connected devices can communicate with cloud-based services to achieve improved human lifestyles [9]. Smart clothing, such as leggings, that can be in direct contact with a large area of the body can ensure comfort, usability, accuracy, product washability, and support real-time monitoring. The focus has been placed on introducing smart leggings for monitoring health, sports and athletics and fashion.

\subsection{Design Requirements \\ 3.2.1. Market Forecasting}

Market experts are expecting a growth of the smart clothing market to USD 6 billion from USD 900 million by 2025 [77]. According to a different report, the global smart textiles market was worth USD 523 million in 2015 and the current prediction shows that the market will grow at a rate of over 34.5\% from 2016 to 2024 [78]. One estimation suggests 
that an amount of clothes worth more than USD 500 billion become unusable every year and approximately 90 per cent of all fashion items are just wasted. It is expected that an unprecedented market expansion will occur in the future due to the advancement in fibre and textile electronics.

\subsubsection{Demand Analysis}

The market of smart clothing is currently in its initial stages; however, it is predicted that the market will grow rapidly in the near future. Therefore, the demand of smart clothing is increasing as solutions are found for more accurate, personalized, and continuous healthcare services. The main benefits of this market are quality of care for individuals through continuous nonintrusive monitoring, light processes and reductions in healthcare costs. Smart clothing also has huge market in sport as it can prevent injury [78].

\subsubsection{Technical, Aesthetic and Targeted User's Requirements}

The technical design and aesthetics are linked to multiple factors, including the user's age, target application, competitors, and fashion trends [78]. As a technical requirement, integration between wearable devices and smart clothing should be ensured according to a certain specification for the accurate monitoring of movements or other physiological signs [7]. The sensor areas of the clothes are to be tight by ensuring proper elasticity at different levels to maximize skin contact during signal recording. They should also be easy to take on and off with no interference in the user's common daily activities. In addition, real-time data processing, specific requirements for washing, ironing, and sterilization should also be considered during the design of smart clothing. The Human body generates sweat and heat, and therefore a balance must be maintained through thermal management by applying transportation and conservation of heat and moisture. Tactile comfort can be ensured by decreasing the dimensions and weight of textile and sensor materials [78]. Smart clothing is intended to be worn for longer than any other wearable devices. Therefore, it should be attractive to users both in terms of design and aesthetics, with a flexible size, as well as being colourful and lightweight. A usability evaluation revealed that most of the users prefer natural materials and a basic colour. However, user groups with a neurological condition are more concerned with the clothes having the capability of health measurement and disease management rather than being aesthetically pleasing, such as through the colour and design [79].

\subsubsection{Conceptual Specification of Smart Leggings}

To develop smart leggings, high-quality polyamide, polyester, LYCRA ${ }^{\circledR}$ and graphenecoated fabrics can be used to ensure breathability, a perfect fit, muscle control, UV protection, quick drying, stretchable, bacteriostatic properties, etc. [80]. The leggings read muscle activity and detect force while performing a physical activity, including running, cycling, climbing and other sports. The leggings acquire muscle signals surrounding the knee joint, which vibrates, and lights up during the recording of muscle activity, one that is prone to injury. A small Bluetooth hardware unit embedded into the leggings can send measurement data in real time to a user's smartphone. Once the data are received by the app, they are analysed using advanced AI algorithms to take further necessary actions. The leggings may send smart notifications to the user's phone to alert them to their health condition and level of fitness. A mobile app that uses inputs of the user's physical attributes and muscle data from the leggings should recommend a rest time. An online dashboard that archives any video data of the user and correlates them with the muscle data is presented in [81]. A conceptual technical specification for future smart leggings is presented in Table 2 
Table 2. Conceptual technical specification for future smart leggings (adapted from [80]).

\begin{tabular}{|c|c|}
\hline Attributes & Specification \\
\hline Size & XS-S, M-L \\
\hline Fabric materials & Polyamide, Polyester and LYCRA, graphene \\
\hline & 3D acceleration sensor with 360-degree high-sensitivity \\
\hline Sensors & vibration motor \\
\hline Communication & $\begin{array}{c}\text { Power management module } \\
\text { Bluetooth } 4.0 \text { or higher wireless technology } \\
\text { Smartphone }\end{array}$ \\
\hline Power and Battery & Self-powering \\
\hline & $\begin{array}{l}\text { Minimal washing (delicate washing conditions), a maximum temperature of } 30^{\circ} \mathrm{C} \\
\text { Wash by hand, maximal temperature } 30^{\circ} \mathrm{C} \text {, handle with care/Washable }\end{array}$ \\
\hline Care Instruction & No bleaching \\
\hline Care Instruction & $\begin{array}{l}\text { Suitable for tumble drying (no heat setting) } \\
\text { Cool iron (Maximum sole-plate temperature of } 110^{\circ} \mathrm{C} \text {, steam-ironing may be a risk) }\end{array}$ \\
\hline App requirement & $\begin{array}{l}\text { No dry cleaning or removing stains with solvents } \\
\text { iOS: } 9.0 \text { or later } \\
\text { Android: } 6.0 \text { or later } \\
\text { Support for Bluetooth } 4.0 \text { or higher } \\
\text { Mobile application }\end{array}$ \\
\hline
\end{tabular}

\subsection{Development of Textile Materials}

Over the past ten years, many innovative materials have been developed and used with the purpose of realising smart clothing. Figure 9 provides categories of selected textile materials for smart clothing.

\section{Textile materials for smart clothing}

Conductive fibres

Material: $\mathrm{CU}, \mathrm{Ag}, \mathrm{Ms}, \mathrm{Al}$, $\mathrm{Ms} / \mathrm{Ag}$

Mechanism: Antistatic, EMI, infrared absorption

Application: Fabrics, shirt, pant etc.
Self-cleaning textile



Self-healing textile

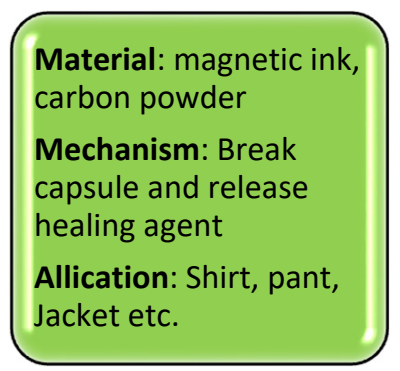

\section{Engnergy-harvesting textile}

Material: AgO-ZN battery, Polymer substrate

Mechanism: Battery fabricated by screen printing

Application: Jacket, shirt etc.

Figure 9. Classification of textile materials for smart clothing.

\subsubsection{Conductive Fibres and Fabrics}

Conductive metal filaments including copper $(\mathrm{Cu})$ and silver-plated copper $(\mathrm{Cu} / \mathrm{Ag})$, brass ( $\mathrm{CuPbZn})$ and silver-plated brass (Ms / $\mathrm{Ag}$ ), and aluminium (Al) to copper-clad aluminium (CCA) are used in smart clothing. Metal monofilaments blended with other textile fibres are used for weaving and knitting [82]. Initially, conductive threads were used in clean room garments, military clothing, medical application and electronics manufacturing [83]. Electrotextiles reveal the conductivity and are used in antistatic applications [84,85], electromagnetic interference shielding (EMI) [86], electronic applications, infrared absorption and in the protection of clothes in explosive areas [87]. A company in Switzerland called Swiss-Shield ${ }^{\circledR}[88]$ has produced metal monofilaments incorporated into base yarns such as cotton, polyester, polyamides and aramides. A conductive yarn with base fibres and a metal monofilament twisted around them is presented in Figure 10. 


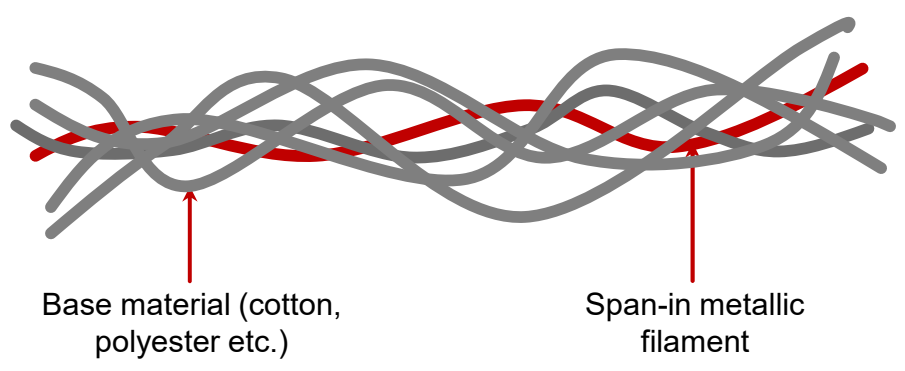

Figure 10. A schematic of conductive fibre twisted with normal fibres.

Electrically conductive fabrics are developed by weaving conductive yarns into the textile structures or applying metallic coatings on the yarn or fabric [89]. Examples of a metal wire twisted around a polymer yarn, a polymer yarn coated with a thin metal layer and a conductive yarn consisting of metal multifilaments are presented in Figure 11. Researchers have developed conductive threads by coating a conventional yarn with metal layers, ELITEX ${ }^{\circledR}$. Nylon 66 threads were coated with a thin silver layer in [90].



(a)

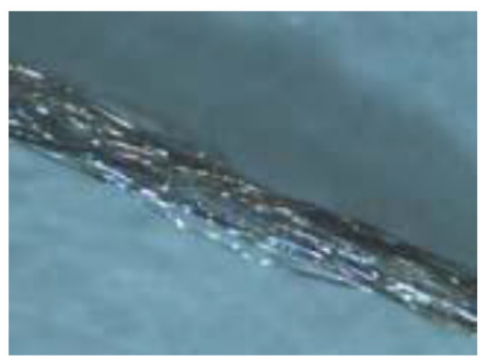

(b)

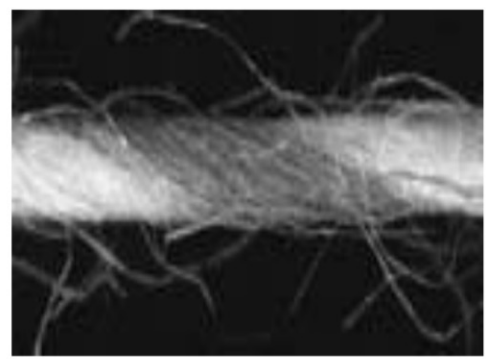

(c)

Figure 11. (a) A metal wire is twisted around a polymer yarn; (b) a polymer yarn coated with a thin metal layer; and (c) a conductive yarn made of metal multifilaments (adapted from [89]).

Researchers have developed a plain-woven textile structure with polyester yarns twisted with one copper thread as shown in Figure 12a. A hybrid fabric called PETEX was developed (Figure 12b) by weaving polyester (PET) monofilament yarns containing copper alloy wires [91]. The copper wires were coated with a polyurethane varnish as electrical insulation. A metallized woven nylon fabric is developed using silver, copper or a combination of copper and nickel [92]. A Danish company has developed weaving electronics into fabrics, electronic conductors in clothing, operating panels in textiles (soft keyboards, displays, etc.) and microsensors. Copper thread was used as conductive yarn, which is plated with a silver layer and coated with a polyester layer [93].



(a)

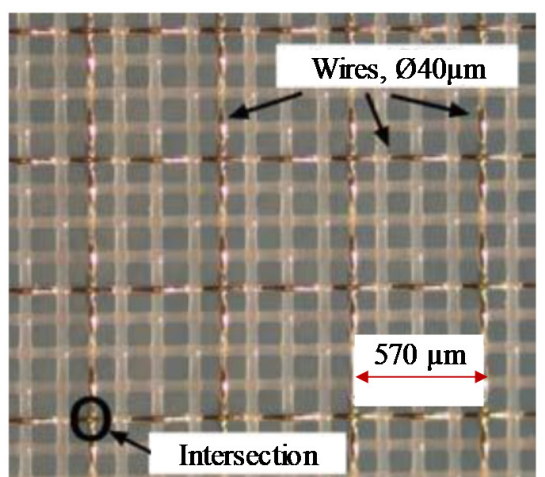

(b)

Figure 12. (a) Standard design of copper yarn twisted with polyester fibres; (b) PETEX (adapted from [89]). 


\subsubsection{Self-Cleaning Textile Materials}

Self-cleaning clothes will be demanded in future fashion due to their automatic washable capability. Attaching tiny metal structures with cotton fibres can break down dirt when exposed to sunlight. Researchers at RMIT University in Melbourne are working to develop a self-cleaning textile by integrating $3 \mathrm{D}$ copper and silver nanostructures woven into a piece of cotton fabric capable of degrading dirt, dust, and sweat when exposed to a concentrated light source. In their research, nanostructures absorb energy after exposure to light and create "hot electrons" to break down the dirt and clean the fabric [94]. A thin layer of titanium dioxide particles is used to coat the fabric [95]. When the sunlight falls on the semi-conductive layer, electrons are excited within the crystal structure and react with oxygen atoms in the air, which creates free-radical oxygen. The oxygen can break down compounds made by carbon using oxidation-reduction reactions. Dirt is then broken down into carbon dioxide and water (Figure 13).
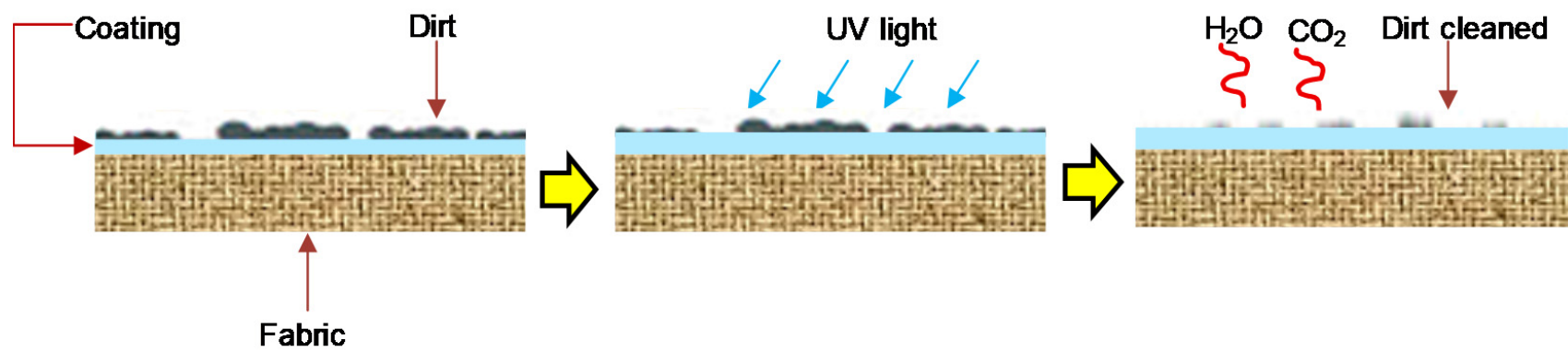

Figure 13. Working principle of self-cleaning fabric.

\subsubsection{Self-Healing Textile Materials}

Embedded devices in smart clothing should have the capability to maintain their basic function after mechanical damage. Self-healing is a way to promote clothes durability to avoid damage. Research is being continued to recover the essential functions of sensors and self-repair capability of clothing [96]. For healing mechanical damage, excessive electrode adhesion and wire bonding are occurred in sensors during operation. Self-healing polymers are prepared as an example through performing a validation of embedding external healing agents and catalysts in a capsule [97]. Large strains break the capsule and healing agents are released into the crack areas to trigger polymerization and the release of molecules [98]. Researchers have found that self-healing magnetic ink can repair itself automatically by healing multiple cuts in milliseconds. Self-healing magnetic ink is used in smart clothing components including batteries, electrochemical sensors, and circuitry. Microscopic particles are inserted into e-ink by crushed up neodymium magnets which are used for creating printed electronic components. In addition, carbon powder is mixed and placed in a magnetic field to raise the ink's conductivity. A design of self-healing fabric is presented in Figure 14.

\subsubsection{Energy-Harvesting Textile Materials}

It is difficult to charge smart clothes every day. Lithium rechargeable batteries are unable to power sensors continuously due to their weak mechanical stability [99]. Smart clothes can extract the energy generated by a human body. Georgia Tech researchers have formed energy-harvesting yarns that are woven into textiles. Static electricity was used, which was generated by the friction of two materials. The fabric sewn into socks, jumpers and other clothes is capable of harvesting energy from the body movement to power a sensor. Infineon, the semiconductor company, is currently working on recovering energy for body movement to feed Mp3 players integrated in a jacket with the use of piezoelectric materials [100]. University of Bolton has developed a technology with the use of piezoelectric polymer substrate and photovoltaic coating system creating a film or fibre structure to harvest energy from the sun, rain, wind and wave [101]. Energy-harvesting film 
in textiles uses printing process for gathering energy through active printed inks [102,103]. Mechanical energy in the form of vibration or motion is converted into an electric current by flexible fibre-coated zinc oxide nanowires. A cost-efficient and scalable method was developed by scientists of RMIT University to fabricate textiles embedded with energy storage devices enabled by graphene supercapacitors. This method is capable of producing a waterproof smart textile patch. The capacitor was connected to a solar cell, which can deliver an efficient, long-lasting and self-powering smart fabric [104,105].

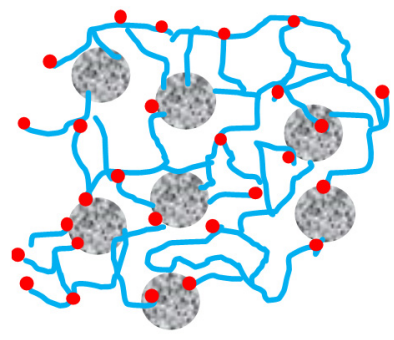

a)



b)

Figure 14. (a) The schematic of interaction of oligomer chains with $\mu$ Ni particles. (b) Optical image of scar healing for the damaged sample (adapted from [5]).

\subsection{Sensor and Sensing Mechanism in Smart Clothing}

The current development of wearable technologies has advanced the monitoring capabilities of various physiological parameters including heartbeat rate, respiration rate, temperature, etc. Mechanical stimulations and concentrations of electrolytes are detected as health indicators where strain, pressure, force and vibration are transduced into electrical parameters such as mechanical stimulations using wearable sensors. These types of detection are performed through piezoresistivity, capacitance, piezoelectricity, etc. [106]. The physiological parameters and sensing mechanisms are presented in Table 3.

Table 3. Different physiological parameters and their sensing mechanisms.

\begin{tabular}{|c|c|c|c|}
\hline Sensing Device & Sensing Mechanism/Characteristics & Sensing Parameters & Reference \\
\hline $\begin{array}{l}\text { Piezoresistive (Carbon } \\
\text { nanotube, LM35) }\end{array}$ & $\begin{array}{l}\text { Changes in microstructure of sensing } \\
\text { films generates electrical resistance } \\
\text { after applying strain while structure } \\
\text { of the device is deformed. }\end{array}$ & $\begin{array}{l}\text { Motion detection, measuring } \\
\text { temperature, } \mathrm{pH} \text {, humidity, etc. }\end{array}$ & {$[107,108]$} \\
\hline $\begin{array}{c}\text { Capacitive (Planar } \\
\text { interdigitated capacitor (IDC)) }\end{array}$ & $\begin{array}{l}\text { Applied strain changes distance } \\
\text { between two electrodes and thus } \\
\text { capacitance is changed. }\end{array}$ & Motion posture Heart/respiration pulse & [109] \\
\hline $\begin{array}{c}\text { Piezoelectric (as } \mathrm{ZnO}, \mathrm{GaN} \\
\text { and PZT) }\end{array}$ & $\begin{array}{l}\text { Electromechanical interaction in } \\
\text { noncentrosymmetric crystal structure } \\
\text { materials generate electric charges by } \\
\text { applying external mechanical stimuli. }\end{array}$ & Lactate, sweat & [110] \\
\hline
\end{tabular}

\subsection{Development in Smart Clothes Sensor Materials}

Researchers are working towards developing wearable sensing devices with flexibility, stretchability and physical robustness. The development of new materials and fabrication strategies are critical factors for ensuring the compatibility of mechanical and functional properties [111]. Figure 15 provides an overview of the sensor materials used for smart clothing. 


\section{Smart cloth sensor materials}


Figure 15. Sensor materials for smart clothing.

\subsubsection{Carbon-Based Sensor Materials}

Graphite

Graphite is a form of carbon that can be used for developing pencil-on-paper electronics. It has become popular due to its good electrical- and heat-conducting properties, light weight and being disposable and flexible [112,113]. Graphite flakes deposited on a paper surface and drawn traces have been used as resistors in resistor-capacitor (RC) filters and transistors. The presence of structural edges in graphite flakes increases the strain-induced resistance variation of traces, making them appropriate for strain gauges. Further overlaps in graphite flakes are developed by compressing the trace that leads to a decreasing resistance.

\section{Graphene}

Graphene has attracted significant research interest for use in smart clothing due to its outstanding electrical, mechanical, optical transmittance, and thermal properties [114-117]. It acts as a platform for both interconnects and active devices such as flexible and stretchable transistors and sensors [115]. It has the ability to interact with oxygen-containing groups in textile fibres and is used as a part of textile rather than forming only a surface coating [118]. Graphene can be used as an electrode material for capacitors. Graphene is a useful material for wearable sensors as it contains huge microribbons to adjust the balance between sensitivity and stretchability.

Graphene-based ink and an inkjet-printing process were used by researchers at the University of Cambridge to print integrated circuits onto fabric [119]. The researchers experimented using low-cost and sustainable graphene, and other 2D materials containing low-boiling inks printed on polyester fabric (Figure 16). It was observed that the durability and performance of the printed devices were improved by modifying the roughness of the fabric.

Researchers from the school of Engineering at The University of British Columbia developed a low-cost graphene-based sensor that can be integrated into textile and composite materials. A microscopic sensor embedded into woven yarns was stretched and used for monitoring human health and detecting motion. A dip-coating process was applied to fabricate a cost effective, tuneable and stretchable sensor on spandex ( $\mathrm{SpX}$ ) yarns coated with graphene nanoplatelets $(\mathrm{GnP})$. Protecting the conductive layer against harsh conditions, the SpX/GnP was wrapped into a stretchable silicone rubber (SR) sheath, allowing for the fabrication of wearable sensors [120].

A consortium of European academics have discovered a way to coat fabric with graphene to create electronic textiles. They deposited graphene onto a copper foil and then 
transferred it onto fibres, paving the way for integrating transportable electronic devices into fabrics. This technology inspired the creation of a T-shirt with GPS capabilities, having a hoodie act as the phone or upholstery for playing music files [121].

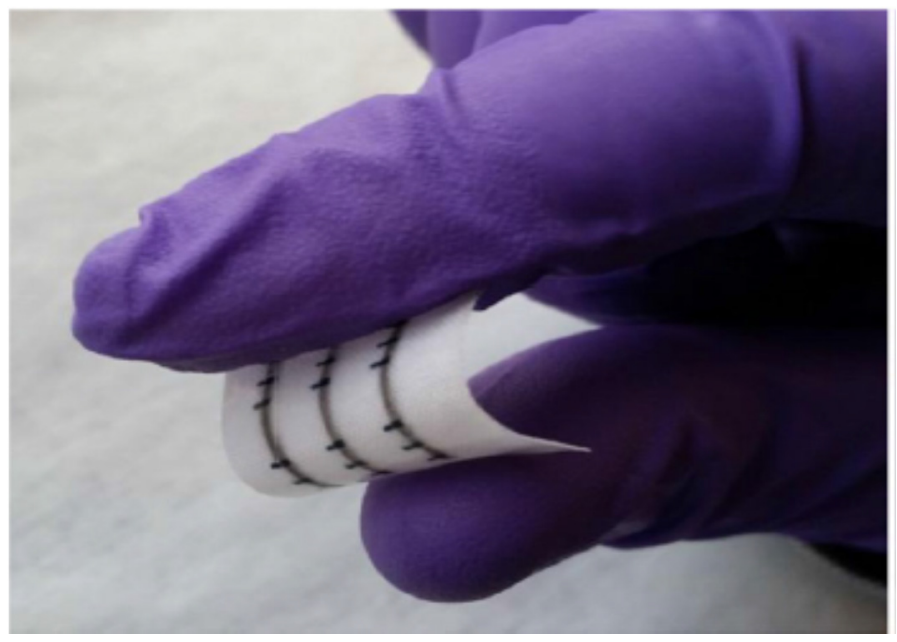

Figure 16. Graphene-based ink and an inkjet-printing process to print integrated circuits onto fabric [119].

A supercapacitor connected to a solar cell to be laser printed directly onto textiles produces an efficient, washable and self-powering smart fabric. Graphene oxides (GOs), amorphous silicon solar module, spandex nylon lycra matte fabrics and Polyvinyl alcohol (PVA)/Sulphur acid $\left(\mathrm{H}_{2} \mathrm{SO}_{4}\right)$ are used as electrolytes in developing laser printed graphenebased supercapacitors [122]. Polydimethylsiloxane (PDMS) was coated on one side of the fabrics and the other side was coated with a GO/Matte binder to form a thin coating.

A graphene-coated textile was fabricated in [123] using a wearable strain sensor. An elastic silicone and polydimethylsiloxane (PDMS) were used to encapsulate the textile. A conductive network was established during stretching with vertical and horizontal fibres of the textile. The sensor without having encapsulation provides a low-cost and scalable fabrication method by extending it to other woven fabrics. The high sensitivity, long-term stability and great comfortability of the sensor allow the real-time monitoring of human physiology activities.

Graphene oxide (GO) is a single-atomic layered material, developed by the oxidation of graphite. GO films are deposited onto substrate to convert it into a conductor. Karim et al. [124] presented a simple, scalable, and cost-effective method that can produce etextiles. Graphene oxide (GO) was employed to ensure stable reduced graphene oxide (rGO) dispersion, which was applied to the textile using simple pad-dry techniques. The laser scribed (LS) technique is useful for putting graphene layers onto various flexible substrates. For example, functional patterns are produced with the use of graphene oxide (GO) films. In addition, the electronic properties of the layer can be adjusted broadly by varying the laser power and irradiation time [125].

\section{Carbone Nanotube (CNT)}

To build wearable devices, CNT powder is often mixed with polymer substrates and its outstanding conductivity is used for constructing sensors. To create electrodes in capacitive sensors, CNT reagent can be placed onto the substrate. Further, the CNT reagent is dispersed into flexible/stretchable polymers to develop piezoresistive composites or films. The network of CNTs has an admirable strain-sensing capacity.

Du et al. [126] presented carbon nanotube (CNT)-based e-textiles used as wearable strain and pressure sensors. The nanosoldering facile method was used to fabricate etextiles by the ultrasonic soldering of CNTs on a nonwoven fabric (NWF) to make conductive textiles. CNTs are used as wearable sensors for monitoring blood pulse. An e-textile 
has been developed for intelligent human-machine interfacing using conductive carbon nanotubes (CNTs) and screen-printing technology [127]. The textile was used as a selfpowered touch/gesture sensor with outstanding performance under washing conditions. The e-textile is constructed in three layers, including a top layer, which consists of silk fabric acting as frictional material, nylon fabric used for the bottom layer as substrate and a $\mathrm{CNT}$ electrode array is used in the middle layer. CNT ink was printed onto nylon fabric to fabricate the electrode array.

\subsubsection{Metal-Based Sensor Material}

Nanowires (NWs) and Nanoparticles (NPs)

Metallic nanowires and nanoparticles are used to prepare piezoresistive composites and conductive ink. Ag NWs can be embedded into Polydimethylsiloxane (PDMS) to build resistive-type sensors. Ag NW film is simply coated on the surface of polymers, and so there is a great possibly to increase resistance due to buckling and wrinkling. Therefore, the Ag NW layer is often sandwiched between two substrate layers [128,129]. To produce electrodes for capacitive sensors, the conductive inks and metal NPs can be casted on the substrate surface. In addition, coiled, serpentine and woven structures of metal materials are used to provide required flexibility and stretchability.

\section{Liquid Metal}

Gallium (Ga) and its alloys are liquid metals that stay in liquid state at room temperature and are a nontoxic alternative to mercury $[130,131]$. Microfluidic techniques are used in constructing stretchable sensors, being combined with liquid metals. The applied mechanical stimulus can change the microchannel geometry by changing the electric resistance, which creates variations in the sectional area and length of the liquid metal resistor. Thus, pressure and strain can be measured and assembled into an RFID tag or antenna to build wearable sensing devices.

\subsubsection{Polymers}

Poly (3,4-ethylenedioxythiophene): Poly (styrene sulfonate) PEDOT: PSS

PEDOT: PSS is a commercialized polymer that is extensively explored in sensing elements as it has thermal stability, and is transparent and conductive. It is also compatible with many conventional processing techniques, such as dipping-drying, spinning coating and inkjet printing due to its solubility in water [132].

\section{Polyvinylidene Difluoride (PVDF)}

PVDF is an energetic material having great properties for piezoelectric wearable sensors. PVDF is used for making flexible sensors in the field of healthcare for monitoring heart rate, respiration, plantar pressure distribution, etc. In addition, organic materials including PPy, P3HT and PANI are utilized to construct wearable sensors [133].

Ionic Liquid (IL) Salt

At present, ionic liquid (IL) salt is used in developing electrochemical sensors, energy devices, and transistors, for keeping liquid state at room temperature. Based on the concept of liquid metals, IL can be embedded into a PDMS-based microchannel to construct strain sensors [134].

\section{Conducting Polymers}

Conducting polymer materials are used for producing smart clothes due to their great output power, high reliability, low-cost characteristics and adaptability in terms of structural design and material choices $[135,136]$. Huang et al. [18] presented a strategy to design and fabricate fibre/fabric-based triboelectric nanogenerators (TENGs) that were knitted from conductive silver-plated nylon threads using a commercially available knitting method. A power-generating polyethylene terephthalate (PET) fabric is developed in [137]. 
Conductive fabric was used as an electrode, attaching onto the back of a different fabric, which can be cut into desired sizes. Then, the fabric was integrated with the garment for harvesting the mechanical energy from human movement.

\subsection{Integration between Sensor and Textile}

The integration of sensors in textile materials can be achieved at different levels for developing smart clothing.

\subsubsection{Integration at the Material Level}

Active sensor materials are doped in polymers and dried elastic composites can be made in bulk or film forms to fulfil the smart clothing application requirements. For example, the performance of a carbon black-silicone composite depends on the filler concentration [138]. Through an encapsulation process, active sensitive materials are sandwiched between substrates to develop a sensitive composite.

\subsubsection{Integration at the Fibre Level}

Researchers from Massachusetts Institute of Technology (MIT) have produced optoelectronic semiconductor-embedded fibres that are woven into soft fabrics using light-emitting diodes (LEDs) and diode photodetectors. The fibre was heated in a furnace during the drawing process where the polymer was liquefied to make a long fibre with the diodes lined up along its centre, connected by copper wires. These fibres can be used for communication and safety, military lighting applications, monitoring physiological parameters, including measuring vital statistics, and monitoring healing, such as in pulse meters and smart bandages [139].

\subsubsection{Integration at the Yarn/Fabric Level}

A fabric embedded with a pressure sensor was developed in [140] by selectively placing polyurethane-coated Ni-Ti alloy yarns during the weaving process of a fabric made of predominantly woollen yarns, as presented in Figure 17. The capacitance of the dielectric material sandwiched between two electrodes varied with the thickness of the material. The fabric enables developing a real-time sitting posture correction system. Conducting thread such as copper $(\mathrm{Cu})$ or silver $(\mathrm{Ag})$ fibres were utilized for the electronic textile $[6,141]$.


Ni-Ti alloy fiber

Figure 17. Textile pressure sensor based on Ni-Ti alloy fibre coated with polyurethane rubber (adapted from [140]).

Electrical engineers from ETH Zurich have developed intelligent textiles with sensors and conductive filaments woven into textiles. This technology is developed by attaching thin-film electronics to the textile. Microchips and other microelectronic elements were integrated directly into the architecture of the material. The microchips were placed on plastic strips and encapsulated [142].

Coating fibres, yarns and fabrics with metals, galvanic substances or metallic salts can create conductive textiles. Electroless plating, evaporative deposition, sputtering and the chemical coating of textiles with a conductive polymer are popular coating processes [5]. To produce the desired geometry of the wearable sensor, pattern transferring is used as 
the fabrication method. The available techniques of pattern transferring are microscale modelling, lithography, screen printing, inkjet printing, 3D printing and handwriting. Researchers at the University of Southampton developed textile-based screen-printed network for electrodes and associated conductive tracks used in healthcare applications. A polyurethane paste was screen printed onto a woven textile to create a smooth and conductive track. A wearable device was developed using silver pastes printed onto nonwoven textiles for health monitoring [6]. The laser scribed (LS) technique is useful for manufacturing sensors, for example, predesigned graphics are set to move the laser beam accordingly and exposed materials are sensitized for sensing different stimuli [5].

\subsubsection{Integration at the Garment Level}

The Austria-based company QUS Sports is in the process of producing smart textiles (shirt and bra) that can track body fitness. Intelligent micro-EMG sensors are placed in a QUS shirt, recording all relevant data via Bluetooth. Monitoring of the heart rate, breathing rate, calorie consumption, acceleration, g-force, geo-data, sleep and regeneration for sports-training is performed by the smart clothing [143].

An embroidery technique can be used to develop a conductive fabric. MIT proposed an approach of stitching patterns that can be defined circuit traces, component connection pads, or sensing surfaces designed with traditional CAD tools for circuit layout [144]. They developed a musical jacket comprising a fabric keypad, a MIDI synthesizer, speakers behind speaker grills in the pockets, fabric buses visible inside the jacket and a fabric keypad with the circuit board placed behind it (Figure 18).

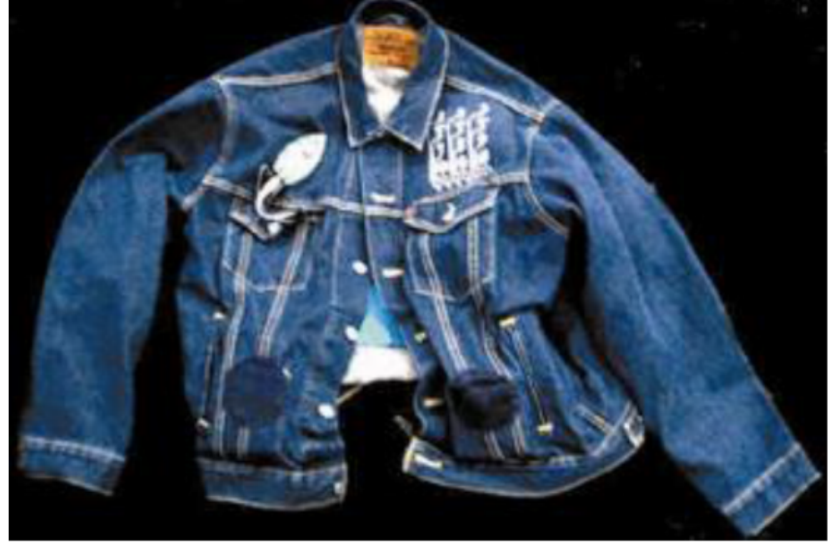

(a)

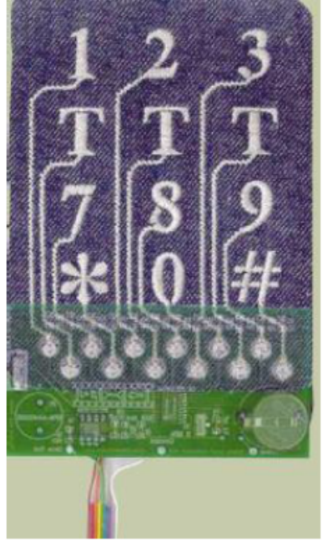

(b)

Figure 18. (a) Musical jacket. (b) Fabric keypad with circuit board placed behind it [89].

\subsection{Data Collection, Data Analytics and Decision Support}

Recent research efforts on data analytics present various healthcare frameworks. Most of the frameworks describe from the stage of data collection up to decision making. However, there is still lack of research providing the details of each stage in their frameworks. For smart clothing, data collection entails capturing raw biosignals from the human body such as ECG, heart bit, blood oxygen, knee movement, etc. The collected raw data are stored in a local hardware-based system or cloud-based system and pre-processed through filtering (eliminating outlier) transforming, categorizing and turning it into a structured form such as an CSV or text file with the use of statistical techniques. An example of ECG data filtering can be found in the author's previous publication [46]. The accurate processing and management of physiological data allows health/fitness monitoring systems to make holistic assessments of patients, personalize treatments, and improve communication. The processed data are then analysed by applying advanced machine learning techniques such as classification, clustering, regression analysis, and deep learning. Finally, a decision is made by the carer or medical advisor based on the outcome from the analysis with the help of a graphical user interface. 


\subsection{Pros and Cons of the Proposed Framework}

The proposed smart clothing framework is suggested for material selection to find a textile and sensor that could be useful to develop durable smart clothes. Most importantly, the framework has suggested an IoT cloud service systems where the signal data are collected from various parts of the human body through internet, processed, and analysed through AI techniques which can provide the best decision-making strategy for taking necessary action before causing any serious health damage. Clothes manufacturing industries can take this idea forward to develop advanced smart clothing technology for identifying any abnormal health condition and taking necessary actions. However, the further development of different technologies required for this framework is important to ensure its effectiveness in real-life applications.

\section{Challenges and Future Development}

This section identifies some challenges for smart clothing considering various aspects and provides possible solutions to overcome them. Firstly, the technical challenges, including a shorter battery life, privacy and the security of collected data, are discussed. Then, this section further discusses the durability of the smart clothing, including the high failure rate, maintenance and washability. The challenges of social acceptability and design and integration have also been identified and critically analysed.

Although some significant developments have been made in smart clothing in the recent past, there are still many challenges left to be addressed. Figure 19 presents the summary of challenges for wearable technology as smart clothing. The following sections discuss individual challenges and suggestions for future development.



Figure 19. Challenges of wearable technology in smart clothing from various perspectives.

\subsection{Technical}

\subsubsection{Noisy and Discontinuous Signals from Sensors}

Physiological signals collected using smart clothing are noisy due to motion artefacts and thus misleading predictions of health condition. Appropriate methods [46] can be employed to filter the noisy monitored signal automatically at the time of data processing. Then, the filtered data can be used for assessing actual health and fitness conditions and taking appropriate actions.

Handling a discontinuous signal generated by an integrated sensor in smart clothing is another challenge $[7,9]$. This may be caused due to any fault appearing in the sensor 
embedded within the clothing. Furthermore, an inappropriate attachment between the sensor and clothing may also generate discontinuous signals. Therefore, the development of reliable wearable sensors and a proper embedment between the sensor and clothing are required to avoid receiving any discontinuous signal.

\subsubsection{Lack of Flexibility, Foldability and Comfortability}

The sizing of wearable products is important for smart clothing as it is difficult to adjust large sensors within clothing for collecting signals. Sometimes, sensors are difficult to bend flexibly and adapt to smart clothing [145]. It is necessary to develop flexible sensors that are as thin as possible for embedding and bending with clothing to collect physiological data accurately. In addition, a new tailoring strategy will help in making flexible smart clothing.

Unfoldable and nonadjustable sensors with smart clothing are not capable of providing accurate information. In smart clothing, electrodes can be used that are foldable and are not seen from the outside as they are covered by the textile.

The continuous contact of wearable devices with human skin can cause discomfort for users. The minimum contact level during moving the body should be maintained to collect data while ensuring user's comfortability to wear for a longer period as regular daily clothes [7].

\subsubsection{Shorter Battery Life and Lack of Self-Powering}

Power failure of the wearable devices may cause serious interruption in monitoring health and fitness condition. Furthermore, the batteries have to power the embedded electronics during monitoring the health-related activities for a long period of time [146].

As wireless networks, GPS, and other technologies consumes lot of power, most of the wearable devices only last for one to two days [147]. Hence, the power can be generated from the body movement. In addition, solar cell systems can be integrated with smart clothing to produce power as an alternative.

\subsubsection{Complicated Interfacing and Operating System}

Without having a suitable user interface, it is difficult to present the monitored parameters to the end-users. Interfacing between smart clothing and a local cloud-based system via Wi-Fi, Bluetooth or mobile network needs to be developed for storing and analysing continuous monitored health-related data to take preventive steps [148]. A customized operating system (OS) specific to smart clothing can be developed for universal application.

\subsubsection{Privacy and Security}

Security and privacy are important for wearable technology as a serious breach of personal information in the form of data could occur, which could lead to financial loss or safety concerns [149]. This might discourage people from using wearable devices. From an IOT device consumer survey, it was estimated that $28 \%$ of respondents are concerned about the hacking of their devices [150]. Therefore, further investigation is required to improve the trustworthiness of the devices in terms of cyber security.

\subsection{Durability, Service Life and Maintenance}

\subsubsection{High Failure Rate}

Intricate processing techniques for sensor development and embedding in clothing make smart clothing highly vulnerable to frequent failure, which raises the question of its reliability in use [7]. Manufacturers should seek alternative processing techniques to develop a robust product that a user can rely on.

\subsubsection{Shorter Lifetime}

Some smart clothing products cannot survive longer in the market; thus, manufacturer and consumers both face financial loss [151]. Therefore, achieving a longer lifetime is one of 
the vital challenges for smart clothing that can be ensured by employing durable materials and the integration technique.

\subsubsection{Difficult to Maintain}

The embedded electronics of smart clothing could be damaged by human fluids such as sweat and thermal regulation. Therefore, smart clothing should have accurate functional capabilities to adapt to the body conditions and be easily maintainable.

\subsubsection{Poor Washability}

It is expected that smart clothing should be compatible for washing [8]. However, the current technological development of wearable devices is still behind in terms of maintaining functionalities after washing. A solution has been suggested in the form of a smart box [9], which can be disassembled at the time of washing. The smart box can be installed when the smart clothing is dried. However, it will be more convenient for users if the smart clothing is washable by developing waterproof technology.

\subsection{Social Acceptability}

\subsubsection{Lack of Awareness of Technological Development}

Government and technology developers can work together to broadcast the news of technological advancement through television, newspapers and social media to increase the awareness of the health benefits of smart clothes.

\subsubsection{Personal Choice or Unwillingness}

According to the report of Piwek et al. [152], health assessment is one of the important factors as the people who are regularly monitoring their health condition with wearable devices are healthier than those who do not have the willingness to do that. The manufacturers should make the smart clothing attractive, fashionable and intelligent in order to influence people's personal choices. An intelligent system needs to be embedded within the smart clothes to do other things instead of just monitoring the health and fitness condition. For example, smart clothes enabled by motion-capture technologies can help in teaching one how to dance or how to play football.

\subsubsection{Unavailability of the Internet}

The internet has a great impact on smart clothing in communicating physiological information for monitoring health of individuals. Low-income, rural, and homebound populations without internet facilities will lag behind and not receive the benefits of using such wearable technologies. The International Telecommunication Union, the United Nations and global information and communications technology statistics have reported that only $53.6 \%$ of people have access to the internet worldwide due to the high cost of internet service, whereas $84 \%$ of households access the internet from home in developed countries [153]. Efforts should be made to improve the accessibility and affordability of the internet.

\subsubsection{Cost of Smart Fabric}

The high cost of smart fabric is an important factor to be considered, particularly for low-income people [154]. However, increasing the number of users through promoting the benefits of smart clothes will promote their mass production, which can bring down the cost to an affordable level for all classes of people.

\subsection{Design and Integration}

\subsubsection{User Comfort and Aesthetics}

The smart clothing design should be focused on suitable sizes and fit with body shapes and minimum weights. Having a fashionable design of smart clothing will increase 
consumers' willingness to buy and wear it. Therefore, it is essential to make attractive designs with innovative fabric materials, colour, fittings, etc. [7].

\subsubsection{Sensor Integration}

The operational reliability of smart clothing depends on the appropriate integration of the sensor on and within textiles. Sensors can be developed in situ or as an extra piece for attachment with textiles. For in situ textile-based sensors, it is important to carefully consider the compatibility of the nontextile component with textile components. For example, while choosing a conductive chemical for coating or printing on textiles, or doping or impregnating with a fibre polymer system, the natural bonding and fixation between those chemicals and textiles should be first considered to ensure high wash fastness. Otherwise, with frequent washing, the connectivity might be lost in the case of sensors coated onto fabrics. Similarly, for an external sensor of electronics being attached to a textile, it is also important to judge the physical and mechanical behaviour such weight, stretch, shrinkage, etc., before selection.

\subsubsection{Design for Targeted Users}

The same clothes are not usually worn by different age groups. Distinct clothing is preferable, subject to various factors within the wearer community and different age groups including sportsman, athletes, spaceman, pilots, autism children, drivers, etc. [6]. Therefore, the product specifications should be different for the various groups based on their own cultures, ethnicities or dress codes.

\section{Conclusions}

This paper has proposed a comprehensive framework for smart leggings as an innovative health monitoring system with the combination of textile and sensor materials to overcome the shortcomings of traditional wearable technologies including discomfort, sensing inaccuracy, and the incapability of long-term monitoring. The overarching aim of the proposed framework is to show the pathways and to present scientific evidence for developing smart clothing to monitor the wearer's health effectively through gathering various physiological indicators of the human body and handling gathered data using a cloud platform through IoT, Wi-Fi, mobile internet, cloud computing, big data and machine learning. The framework combines various stages, including the design stage and finding a suitable textile and sensor material, and sensor-integration techniques with clothing, signal collection, processing, and decision making. After assessing the material characteristics, a graphene-based material has been selected as the suitable material for making smart leggings. Conductive metal fibre materials such as silver-plated copper $(\mathrm{Cu} / \mathrm{Ag})$ filaments, brass (Ms) and silver-plated brass (Ms/Ag) filaments and aluminium (Al) filaments can be used, whereas 3D copper and silver nanostructures have been identified as suitable textile materials. Carbon-based materials such as graphene and carbon nanotubes are identified as the promising sensor materials for developing smart clothes. In addition, a conceptual specification has also been provided for developing smart clothing (smart leggings). The proposed framework can be applied for developing smart clothes (smart leggings) to enhance operation and quality of life through monitoring various physical indicators and provides value-added service in healthcare, particularly for elderly people, and can track fitness data for sportsmen and athletes. The framework is capable of alleviating existing challenges identified from previous research, including technical issues (noisy signal, shorter battery life, and high-power consumption), durability, service life and maintenance (high failure rate and poor washability), poor social acceptability, and poor design and integration. The proposed framework will support companies and designers to develop innovative smart textiles and technology that will undoubtedly change the way of human life. 
Author Contributions: All authors have equal contribution to prepare and finalize the manuscript. Conceptualization, M.A., S.H.T., A.S.M.S. and A.A.; methodology, M.A., S.H.T., A.S.M.S. and A.A.; validation, M.A., S.H.T., A.S.M.S. and A.A.; formal analysis, M.A. and A.A.; investigation, M.A., S.H.T., A.S.M.S. and A.A.; resources, M.A. and A.A.; data curation, M.A. and A.A.; writing-original draft preparation, M.A., S.H.T. and A.S.M.S.; writing-review and editing, M.A., S.H.T., A.S.M.S. and A.A.; visualization, M.A., S.H.T. and A.A.; supervision, A.S.M.S. and A.A.; project administration, M.A. and A.A. All authors have read and agreed to the published version of the manuscript.

Funding: This research received no external funding.

Institutional Review Board Statement: Not applicable.

Informed Consent Statement: Not applicable.

Data Availability Statement: The data presented in this study are available in this article.

Acknowledgments: The authors would like to thank the team of Manchester Met University for their all kinds of support for this research work and preparing the manuscript.

Conflicts of Interest: The authors declare no conflict of interest.

\section{References}

1. European Commission. Smart Wearables Reflection and Orientation Paper; Technical Report; European Commission: Brussels, Belgium, 2016. Available online: Ec.europa.eu/newsroom/document.cfm?doc_id=40542 (accessed on 31 November 2020).

2. Gonçalves, C.; Silva, A.; Gomes, J.; Simoes, R. Wearable E-Textile Technologies: A Review on Sensors, Actuators and Control Elements. Inventions 2018, 3, 14. [CrossRef]

3. Smart Textiles Market to 2024. Available online: https://www.ameriresearch.com/product/smart-textiles-market/ (accessed on 28 February 2021).

4. IEC TC 124 Strategic Business Plan. Available online: https:/ / www.iec.ch/public/miscfiles/sbp/124.pdf (accessed on 31 January 2021).

5. Liu, Y.; Wang, H.; Zhao, W.; Zhang, M.; Qin, H.; Xie, Y. Flexible, Stretchable Sensors for Wearable Health Monitoring: Sensing Mechanisms, Materials, Fabrication Strategies and Features. Sensors 2018, 18, 645. [CrossRef]

6. Chen, M.; Ma, Y.; Song, J.; Lai, C.F.; Hu, B. Smart Clothing: Connecting Human with Clouds and Big Data for Sustainable Health Monitoring. Mob. Netw. Appl. 2016, 21, 825-845. [CrossRef]

7. Fernández-Caramés, T.M.; Fraga-Lamas, P. Towards the Internet of Smart Clothing: A Review on IoT Wearables and Garments for Creating Intelligent Connected E-Textiles. Electronics 2018, 7, 405. [CrossRef]

8. Muhammad Sayem, A.S.; Hon Teay, S.; Shahariar, H.; Luise Fink, P.; Albarbar, A. Review on Smart Electro-Clothing Systems (SeCSs). Sensors 2020, 20, 587. [CrossRef] [PubMed]

9. Chen, M.; Ma, Y.; Li, Y.; Wu, D.; Zhang, Y.; Youn, C. Wearable 2.0: Enabling Human-Cloud Integration in Next Generation Healthcare Systems. IEEE Commun. Mag. 2017, 55, 54-61. [CrossRef]

10. Meyer, J.; Arnrich, B.; Schumm, J.; Troster, G. Design and modeling of a textile pressure sensor for sitting posture classification. IEEE Sens. J. 2010, 10, 1391-1398.

11. Liang, Z.; Nishimura, T. Are wearable EEG devices more accurate than fitness wristbands for home sleep Tracking? Comparison of consumer sleep trackers with clinical devices. In Proceedings of the 2017 IEEE 6th Global Conference on Consumer Electronics (GCCE), Nagoya, Japan, 24-27 October 2017; pp. 1-5.

12. Joshi, J.; Kurian, D.; Bhasin, S.; Mukherjee, S.; Awasthi, P.; Sharma, S.; Mittal, S. Health Monitoring Using Wearable Sensor and Cloud Computing. In Proceedings of the International Conference on Cybernetics, Robotics and Control, Hong Kong, China, 19-21 August 2016; pp. 104-108.

13. Abtahi, F.; Ji, G.; Lu, K.; Rödby, K.; Seoane, F. A knitted garment using intarsia technique for Heart Rate Variability biofeedback: Evaluation of initial prototype. In Proceedings of the 37th Annual International Conference of the IEEE Engineering in Medicine and Biology Society, Milan, Italy, 25-29 August 2015.

14. Brady, S.; Dunne, L.E.; Tynan, R.; Diamond, D.; Smyth, B.; O'Hare, G.M.P. Garment-based monitoring of respiration rate using a foam pressure sensor. In Proceedings of the Ninth IEEE International Symposium on Wearable Computers (ISWC'05), Osaka, Japan, 18-21 October 2005; pp. 214-215.

15. Spulber, I.; Chen, Y.-M.; Papi, E.; Anastasova-Ivanova, S.; Bergmann, J.; McGregor, A.H.; Georgiou, P. Live demonstration: Wearable electronics for a smart garment aiding rehabilitation. In Proceedings of the IEEE International Symposium on Circuits and Systems (ISCAS), Lisbon, Portugal, 24-27 May 2015; p. 1912.

16. Wang, Q.; De Baets, L.; Timmermans, A.; Chen, W.; Giacolini, L.; Matheve, T.; Markopoulos, P. Motor Control Training for the Shoulder with Smart Garments. Sensors 2017, 17, 1687. [CrossRef]

17. Glucotrack Official Webpage. Available online: http://www.glucotrack.com.au/ (accessed on 31 March 2021).

18. Lowdownfocus Official Webpage. Available online: https://www.smithoptics.com/us/lowdownfocus (accessed on 30 April 2021). 
19. Perego, P.; Andreoni, G.; Zanini, R.; Bellù, R. Wearable biosignal monitoring system for newborns. In Proceedings of the 4th International Conference on Wireless Mobile Communication and Healthcare-Transforming Healthcare Through Innovations in Mobile and Wireless Technologies (MOBIHEALTH), Athens, Greece, 3-5 November 2014; pp. 271-274.

20. Linti, C.; Horter, H.; Osterreicher, P.; Planck, H. Sensory baby vest for the monitoring of infants. In Proceedings of the International Workshop on Wearable and Implantable Body Sensor Networks (BSN'06), Cambridge, MA, USA, 3-5 April 2006.

21. Morales, I.J.C.; Pupiales, S.K.N.; Criollo, A.C.U.; Montalvo, P.D.R. Wearable Textil for Accident Prevention for Babies in Crawl Phase. In Proceedings of the International Conference on Information Systems and Computer Science (INCISCOS), Quito, Ecuador, 23-25 November 2017; pp. 66-72.

22. Ferreira, A.G.; Fernandes, D.; Branco, S.; Monteiro, J.L.; Cabral, J.; Catarino, A.P.; Rocha, A.M. A smart wearable system for sudden infant death syndrome monitoring. In Proceedings of the 2016 IEEE International Conference on Industrial Technology (ICIT), Taipei, Taiwan, 14-17 March 2016; pp. 1920-1925.

23. Frydrysiak, M.; Tesiorowski, L. Health monitoring system for protecting elderly people. In Proceedings of the International Multidisciplinary Conference on Computer and Energy Science, Split, Croatia, 13-15 July 2016; pp. 1-6.

24. Burns, W.P. Evaluation of a technology enabled garment for older walkers. In Proceedings of the Annual International Conference of the IEEE Engineering in Medicine and Biology Society, San Diego, CA, USA, 28 August-1 September 2012; pp. $2100-2103$.

25. Harms, H.; Amft, O.; Tröster, G. Estimating Posture-Recognition Performance in Sensing Garments Using Geometric Wrinkle Modeling. IEEE Trans. Inf. Technol. Biomed. 2010, 14, 1436-1445. [CrossRef]

26. Lin, W.-Y.; Chou, W.-C.; Tsai, T.-H.; Lin, C.-C.; Lee, M.-Y. Development of a Wearable Instrumented Vest for Posture Monitoring and System Usability Verification Based on the Technology Acceptance Model. Sensors 2016, 16, 2172. [CrossRef]

27. Zaffalon Júnior, J.R.; Viana, A.O.; de Melo, G.E.L.; De Angelis, K. The impact of sedentarism on heart rate variability (HRV) at rest and in response to mental stress in young women. Physiol. Rep. 2018, 6, e13873. [CrossRef] [PubMed]

28. Kańtoch, E. Recognition of Sedentary Behavior by Machine Learning Analysis of Wearable Sensors during Activities of Daily Living for Telemedical Assessment of Cardiovascular Risk. Sensors 2018, 18, 3219. [CrossRef] [PubMed]

29. Farooq, M.; Sazonov, E. A Novel Wearable Device for Food Intake and Physical Activity Recognition. Sensors 2016, $16,1067$. [CrossRef] [PubMed]

30. Garcìa, L.; Parra, L.; Jimenez, J.M.; Lloret, J. Physical Wellbeing Monitoring Employing Non-Invasive Low-Cost and Low-Energy Sensor Socks. Sensors 2018, 18, 2822. [CrossRef]

31. Yang, K.; Isaia, B.; Brown, L.J.E.; Beeby, S. E-Textiles for Healthy Ageing. Sensors 2019, 19, 4463. [CrossRef] [PubMed]

32. Yang, L.; Lu, K.; Diaz-Olivares, J.A.; Seoane, F.; Lindecrantz, K.; Forsman, M.; Abtahi, F.; Eklund, J.A.E. Towards SmartWork Clothing for Automatic Risk Assessment of Physical Workload. IEEE Access 2018, 6, 40059-40072. [CrossRef]

33. Scataglini, S.; Andreoni, G.; Gallant, J. A Review of Smart Clothing in Military. In Proceedings of the Workshop on Wearable Systems and Applications, Florence, Italy, 19-22 May 2015.

34. Friedl, K.E. Military applications of soldier physiological monitoring. J. Sci. Med. Sport 2018, 21, 1147-1153. [CrossRef]

35. Tartare, G.; Zeng, X.; Koehl, L. Development of a wearable system for monitoring the firefighter's physiological state. In Proceedings of the IEEE Industrial Cyber-Physical Systems (ICPS), St. Petersburg, Russia, 15-18 May 2018; pp. 561-566.

36. $\mathrm{Bu}, \mathrm{Y}$.; Wu, W.; Zeng, X.; Koehl, L.; Tartare, G. A wearable intelligent system for real time monitoring firefighter's physiological state and predicting dangers. In Proceedings of the IEEE 16th International Conference on Communication Technology (ICCT), Hangzhou, China, 18-20 October 2015; pp. 429-432.

37. Curone, D.; Secco, D.L.; Tognetti, A.; Loriga, G.; Dudnik, G.; Risatti, M.; Whyte, R.; Bonfiglio, A.; Magenes, G. Smart Garments for Emergency Operators: The ProeTEX Project. IEEE Trans. Inf. Technol. Biomed. 2010, 14, 694-701. [CrossRef]

38. Mohammed, A.; Seeam, A.; Bellekens, X.; Nieradzinska, K.; Ramsurrun, V. Gesture based IoT light control for smart clothing. In Proceedings of the IEEE International Conference on Emerging Technologies and Innovative Business Practices for the Transformation of Societies (EmergiTech), Balaclava, Mauritius, 3-6 August 2016; pp. 139-142.

39. Kishore, K.R.N.G.; Rajeshwari, K. Interactive clothes based on IoT using NFC and Mobile Application. In Proceedings of the IEEE 7th Annual Computing and Communication Workshop and Conference (CCWC), Las Vegas, NV, USA, 9-11 January 2017; pp. 1-4.

40. Pacaux-Lemoine, M.; Habib, L.; Tartare, G.; Koehl, L.; Zeng, X. Human-robots cooperation through intelligent garment. In Proceedings of the IEEE 26th International Symposium on Industrial Electronics (ISIE), Edinburgh, UK, 19-21 June 2017; pp. 1996-2001.

41. AL-Haddad, M.A.S.M.; Jamel, N.; Nordin, A.N. Flexible Antenna: A Review of Design, Materials, Fabrication, and Applications. In Journal of Physics: Conference Series; IOP Publishing: Bristol, UK, 2021; Volume 1878, p. 012068.

42. Ali Khan, M.U.; Raad, R.; Tubbal, F.; Theoharis, P.I.; Liu, S.; Foroughi, J. Bending Analysis of Polymer-Based Flexible Antennas for Wearable, General IoT Applications: A Review. Polymers 2021, 13, 357. [CrossRef]

43. Chin, K.S.; Wu, C.S.; Shen, C.L.; Tsai, K.C. Designs of textile antenna arrays for smart clothing applications. Autex Res. J. 2018, 18, 295-307. [CrossRef]

44. Almohammed, B.; Ismail, A.; Sali, A. Electro-textile wearable antennas in wireless body area networks: Materials, antenna design, manufacturing techniques, and human body consideration-A review. Text. Res. J. 2021, 91, 646-663. [CrossRef]

45. Fernández-Caramés, T.M.; Fraga-Lama, P. A Review on the Use of Blockchain for the Internet-of-Things. IEEE Access 2018, 6, 32979-33001. [CrossRef] 
46. Ahsan, M.; Hon, S.T.; Albarbar, A. Development of Novel Big Data Analytics Framework for Smart Clothing. IEEE Access 2020, 8 , 146376-146394. [CrossRef]

47. Min, J.; Sempionatto, J.R.; Teymourian, H.; Wang, J.; Gao, W. Wearable electrochemical biosensors in North America. Biosens. Bioelectron. 2021, 172, 112750. [CrossRef] [PubMed]

48. Talkhooncheh, A.H.; Yu, Y.; Agarwal, A.; Kuo, W.W.T.; Chen, K.C.; Wang, M.; Emami, A. A Biofuel-Cell-Based Energy Harvester With 86\% Peak Efficiency and 0.25-V Minimum Input Voltage Using Source-Adaptive MPPT. IEEE J. Solid State Circuits 2020, 56, 715-728. [CrossRef]

49. Gao, W.; Emaminejad, S.; Nyein, H.Y.Y.; Challa, S.; Chen, K.; Peck, A.; Javey, A. Fully integrated wearable sensor arrays for multiplexed in situ perspiration analysis. Nature 2016, 529, 509-514. [CrossRef]

50. Xu, C.; Yang, Y.; Gao, W. Skin-interfaced sensors in digital medicine: From materials to applications. Matter 2020, 2, 1414-1445. [CrossRef]

51. Gao, Y.; Ota, H.; Schaler, E.W.; Chen, K.; Zhao, A.; Gao, W.; Javey, A. Wearable microfluidic diaphragm pressure sensor for health and tactile touch monitoring. Adv. Mater. 2017, 29, 1701985. [CrossRef]

52. Sun, H.; Zhang, Z.; Hu, R.Q.; Qian, Y. Wearable communications in 5G: Challenges and enabling technologies. IEEE Veh. Technol. Mag. 2018, 13, 100-109. [CrossRef]

53. Alhussein, M.; Muhammad, G. Voice pathology detection using deep learning on mobile healthcare framework. IEEE Access 2018, 6, 41034-41041. [CrossRef]

54. Yuan, X.; Tian, H.; Wang, H.; Su, H.; Liu, J.; Taherkordi, A. Edge-enabled wbans for efficient qos provisioning healthcare monitoring: A two-stage potential game-based computation offloading strategy. IEEE Access 2020, 8, 92718-92730. [CrossRef]

55. Pace, P.; Aloi, G.; Gravina, R.; Caliciuri, G.; Fortino, G.; Liotta, A. An edge-based architecture to support efficient applications for healthcare industry 4.0. IEEE Trans. Ind. Inform. 2018, 15, 481-489. [CrossRef]

56. Yang, B.; Cao, X.; Bassey, J.; Li, X.; Qian, L. Computation offloading in multi-access edge computing: A multi-task learning approach. IEEE Trans. Mob. Comput. 2020, 20, 2745-2762. [CrossRef]

57. Yang, B.; Cao, X.; Li, X.; Zhang, Q.; Qian, L. Mobile-edge-computing-based hierarchical machine learning tasks distribution for IIoT. IEEE Internet Things J. 2019, 7, 2169-2180. [CrossRef]

58. Abdel-Basset, M.; Manogaran, G.; Gamal, A.; Chang, V. A novel intelligent medical decision support model based on soft computing and IoT. IEEE Internet Things J. 2019, 7, 4160-4170. [CrossRef]

59. Yang, J.; Wang, R.; Guan, X.; Hassan, M.M.; Almogren, A.; Alsanad, A. AI-enabled emotion-aware robot: The fusion of smart clothing, edge clouds and robotics. Future Gener. Comput. Syst. 2020, 102, 701-709. [CrossRef]

60. Chen, M.; Li, W.; Hao, Y.; Qian, Y.; Humar, I. Edge cognitive computing based smart healthcare system. Future Gener. Comput. Syst. 2018, 86, 403-411. [CrossRef]

61. Resistat Fiber Collection. Available online: http:/ / www.resistat.com/ (accessed on 12 April 2021).

62. Stoppa, M.; Chiolerio, A. Wearable electronics and smart textiles: A critical review. Sensors 2014, 14, 11957-11992. [CrossRef]

63. Ahsan, M.; Stoyanov, S.; Bailey, C.; Albarbar, A. Developing computational intelligence for smart qualification testing of electronic products. IEEE Access 2020, 8, 16922-16933. [CrossRef]

64. Satinet, C.; Fouss, F. A Supervised Machine Learning Classification Framework for Assessing the Sustainability of Clothing Products. Sustainability 2022, 14, 1334. [CrossRef]

65. Zakynthinaki, M.S.; Kapetanakis, T.N.; Lampou, A.; Ioannidou, M.P.; Vardiambasis, I.O. A Neural Network Model for Estimating the Heart Rate Response to Constant Intensity Exercises. Signals 2021, 2, 852-862. [CrossRef]

66. Foysal, K.H.; Chang, H.J.; Bruess, F.; Chong, J.W. SmartFit: Smartphone application for garment fit detection. Electronics 2021, 10, 97. [CrossRef]

67. Yu, Y.; Li, M.; Liu, L.; Li, Y.; Wang, J. Clinical big data and deep learning: Applications, challenges, and future outlooks. In Big Data Mining and Analytics; Auerbach Publications: Boca Raton, FL, USA, 2019; Volume 2, pp. 288-305.

68. Ravì, D.; Wong, C.; Lo, B.; Yang, G. A Deep Learning Approach to on-Node Sensor Data Analytics for Mobile or Wearable Devices. IEEE J. Biomed. Health Inform. 2017, 21, 56-64. [CrossRef] [PubMed]

69. Hong, W.; Xiong, Z.; Zheng, N.; Weng, Y. A Medical-History-Based Potential Disease Prediction Algorithm. IEEE Access 2019, 7, 131094-131101. [CrossRef]

70. Turner, A.; Hayes, S. The Classification of Minor Gait Alterations Using Wearable Sensors and Deep Learning. IEEE Trans. Biomed. Eng. 2019, 66, 3136-3145. [CrossRef]

71. Jin, H.; Jin, Q.; Jian, J. Smart Materials for Wearable Healthcare Devices. In Wearable Technologies; InTech: Rijeka, Italy, 2018.

72. Jang, Y.; Kim, S.M.; Spinks, G.M.; Kim, S.J. Carbon Nanotube Yarn for Fiber Shaped Electrical Sensors, Actuators, and Energy Storage for Smart Systems. Adv. Mater. 2019, 32, 1902670. [CrossRef]

73. Servati, A.; Zou, L.; Wang, Z.J.; Ko, F.; Servati, P. Novel Flexible Wearable Sensor Materials and Signal Processing for Vital Sign and Human Activity Monitoring. Sensors 2017, 17, 1622. [CrossRef]

74. Mora, H.M.; Gil, D.; Terol, R.M.; López, J.A.; Szymanski, J. An IoT-Based Computational Framework for Healthcare Monitoring in Mobile Environments. Sensors 2017, 17, 2302. [CrossRef]

75. Hu, L.; Yang, J.; Chen, M.; Qian, Y.; Rodrigues, J.J.P.C. SCAI-SVSC: Smart clothing for effective interaction with a sustainable vital sign collection. Future Gener. Comput. Syst. 2017, 86, 329-338. [CrossRef] 
76. Miao, Y.; Wu, G.; Liu, C.; Hossain, M.S.; Muhammad, G. Green Cognitive Body Sensor Network: Architecture, Energy Harvesting, and Smart Clothing-Based Applications. IEEE Sens. J. 2019, 19, 8371-8378. [CrossRef]

77. Smart Fabrics. 2020. Available online: https://www.thehindubusinessline.com/specials/technophile/smart-fabrics-are-poisedto-change-the-clothing-industry/article26934897.ece (accessed on 27 October 2020).

78. Andreoni, G.; Standoli, C.E.; Perego, P. Defining Requirements and Related Methods for Designing Sensorized Garment. Sensors 2016, 16, 769. [CrossRef] [PubMed]

79. Murphy, M.A.; Bergquist, F.; Hagström, B.; Hernández, N.; Johansson, D.; Ohlsson, F.; Sandsjö, L.; Wipenmyr, J.; Malmgren, K. An upper body garment with integrated sensors for people with neurological disorders-Early development and evaluation. BMC Biomed. Eng. 2019, 1, 3. [CrossRef] [PubMed]

80. Smart Tops and Leggings. Available online: https:/ /www.exisom.com/fabrics/ (accessed on 15 April 2021).

81. SMART Knee Sleeve. Available online: https://gadgetsandwearables.com/2016/11/04/smart-knee-sleeve-recommends-rest/ (accessed on 31 May 2021).

82. Elektrisola Feindraht AG. Available online: www.textile-wire.com (accessed on 16 February 2021).

83. Products Emglare. Available online: https:/ / emglare.com/products (accessed on 16 February 2021).

84. Redström, M.; Redström, J.; Mazé, R. IT + Textiles, 1st ed.; The Interactive Institute: Boràs, Sweden, 2005; pp. 59-93.

85. Sophitex Ltd. Available online: http:/ / www.sophitex.com (accessed on 16 June 2021).

86. LessEMF. Available online: http:/ / www.lessemf.com/fabric.html (accessed on 15 January 2021).

87. McFarland, E.G.; Carr, W.W.; Sarma, D.S.; Dorrity, J.L. Effects of Moisture and Fiber Type on Infrared Absorption of Fabrics. Text. Res. J. 1999, 69, 607-615. [CrossRef]

88. Spoerry \& Co AG, Swiss Shield ${ }^{\circledR}$. Available online: www.swiss-shield.ch (accessed on 13 May 2021).

89. Moradi, B.; Fernández-García, R.; Gil, I. E-Textile embroidered metamaterial transmission line for signal propagation control. Materials 2018, 11, 955. [CrossRef]

90. Scheibner, W.; Feustel, M.; Moehring, U.; Hofmann, J.; Linz, T. Textile electrical connecting cables. Band Und Flechtind. 2003, 40, 76-78.

91. Locher, I. Technologies for System-on-Textile Integration. Ph.D. Thesis, Swiss Federal Institute of Technology (ETH), Zurich, Switzerland, 2006.

92. Thermshield. Available online: http://www.thermshield.com/ThermshieldPages/MetallizedFabric.html (accessed on 12 April 2021).

93. Ohmatex, Smart Textile Technology. Available online: http:/ /www.ohmatex.dk (accessed on 3 May 2021).

94. Self-Cleaning Clothing. Available online: https://www.digitaltrends.com/cool-tech/self-cleaning-clothes-rmit-nano-enhancedtextile/ (accessed on 12 February 2021).

95. Malik, T.; Nogja, S.; Goyal, P. Self-Cleaning Textile-An Overview. Available online: https://www.technicaltextile.net/articles/ self-cleaning-textile-an-overview-2646 (accessed on 10 March 2021).

96. Liao, X.; Zhang, Z.; Liao, Q.; Liang, Q.; Ou, Y.; Xu, M.; Li, M.; Zhang, G.; Zhang, Y. Flexible and printable paper-based strain sensors for wearable and large-area green electronics. Nanoscale 2016, 8, 13025-13032. [CrossRef]

97. White, S.R.; Sottos, N.; Geubelle, P.; Moore, J.; Kessler MRSriram, S.; Brown, E.; Viswanathan, S. Autonomic healing of polymer composites. Nature 2001, 409, 794-797. [CrossRef]

98. Dohler, D.; Michael, P.; Binder, W.H. CuAAC-based click chemistry in self-healing polymers. Acc. Chem. Res. 2017, 50, 2610-2620. [CrossRef]

99. Du, B.; Yang, D.; She, X.; Yuan, Y.; Mao, D.; Jiang, Y.; Lu, F. MoS2-based all-fiber humidity sensor for monitoring human breath with fast response and recovery. Sens. Actuators B Chem. 2017, 251, 180-184. [CrossRef]

100. Seo, M.-H.; Yang, H.-H.; Choi, K.-W.; Lee, J.-S.; Yoon, J.-B. A simple breathing rate-sensing method exploiting a temporarily condensed water layer formed on an oxidized surface. Appl. Phys. Lett. 2015, 106, 053701. [CrossRef]

101. Li, H.; Xu, Y.; Li, X.; Chen, Y.; Jiang, Y.; Zhang, C.; Lu, B.; Wang, J.; Ma, Y.; Chen, Y. Epidermal inorganic optoelectronics for blood oxygen measurement. Adv. Healthc. Mater. 2017, 6, 1601013. [CrossRef] [PubMed]

102. Sciacqua, A.; Valentini, M.; Gualtieri, A.; Perticone, F.; Faini, A.; Zacharioudakis, G.; Karatzanis, I.; Chiarugi, F.; Assimakopoulou, C.; Meriggi, P. Validation of a flexible and innovative platform for the home monitoring of heart failure patients: Preliminary results. In Proceedings of the 36th Annual Computers in Cardiology Conference, Park City, UT, USA, 13-16 September 2009; pp. 97-100.

103. Chiarugi, F.; Karatzanis, I.; Zacharioudakis, G.; Meriggi, P.; Rizzo, F.; Stratakis, M.; Louloudakis, S.; Biniaris, C.; Valentini, M.; Rienzo, M.D. Measurement of heart rate and respiratory rate using a textile-based wearable device in heart failure patients. In Proceedings of the Computers in Cardiology, Bologna, Italy, 14-17 September 2008; pp. 901-904.

104. RMIT University. Laser Printing Tech Produces Waterproof e-Textiles in Minutes: A Rapid, Cost-Efficient and Scaleable Method for Fabricating Textiles Embedded with Energy Storage Devices. ScienceDaily. Available online: www.sciencedaily.com/releases/ 2019/08/190827101603.htm (accessed on 27 April 2021).

105. Thekkekara, L.V.; Gu, M. Large-scale waterproof and stretchable textile-integrated laser- printed graphene energy storages. Sci. Rep. 2019, 9, 11822. [CrossRef] [PubMed]

106. Michael, B.; Howard, M. Activity recognition with wearable sensors on loose clothing. PLoS ONE 2017, 12, e0184642. [CrossRef] [PubMed] 
107. Trung, T.Q.; Ramasundaram, S.; Hwang, B.U.; Lee, N.E. An all-elastomeric transparent and stretchable temperature sensor for body-attachable wearable electronics. Adv. Mater. 2006, 28, 502-509. [CrossRef] [PubMed]

108. Kantoch, E.; Augustyniak, P. Human activity surveillance based on wearable body sensor network. Comput. Cardiol. 2012, 39, 325-328.

109. Chortos, A.; Bao, Z.N. Skin-inspired electronic devices. Mater. Today 2014, 17, 321-331. [CrossRef]

110. Bandodkar, A.J.; Hung, V.W.; Jia, W.; Valdés-Ramírez, G.; Windmiller, J.R.; Martinez, A.G.; Ramírez, J.; Chan, G.; Kerman, K.; Wang, J. Tattoo-based potentiometric ion-selective sensors for epidermal pH monitoring. Analyst 2013, 138, 123-128. [CrossRef]

111. Ren, J.; Wang, C.; Zhang, X.; Carey, T.; Chen, K.; Yin, Y.; Torrisi, F. Environmentally friendly conductive cotton fabric as flexible strain sensor based on hot press reduced graphene oxide. Carbon N. Y. 2017, 111, 622-630. [CrossRef]

112. Kurra, N.; Kulkarni, G.U. Pencil-on-paper: Electronic devices. Lab Chip 2013, 13, 2866-2873. [CrossRef]

113. Kong, J.-H.; Jang, N.-S.; Kim, S.-H.; Kim, J.-M. Simple and rapid micropatterning of conductive carbon composites and its application to elastic strain sensors. Carbon 2014, 77, 199-207. [CrossRef]

114. Novoselov, K.S.; Geim, A.K.; Morozov, S.V.; Jiang, D.; Zhang, Y.; Dubonos, S.V.; Grigorieva, I.V.; Firsov, A.A. Electric Field Effect in Atomically Thin Carbon Films. Science 2004, 306, 666-669. [CrossRef] [PubMed]

115. Geim, A.K. Graphene: Status and Prospects. Science 2009, 324, 1530-1534. [CrossRef]

116. He, Q.; Wu, S.; Yin, Z.; Zhang, H. Graphene-Based Electronic Sensors. Chem. Sci. 2012, 3, 1764-1772. [CrossRef]

117. Karim, N.; Afroj, S.; Tan, S.; He, P.; Fernando, A.; Carr, C.; Novoselov, K.S. Scalable Production of Graphene-Based Wearable E-Textiles. ACS Nano 2017, 11, 12266-12275. [CrossRef] [PubMed]

118. Wearable Technologies. Available online: https://www.wearable-technologies.com/2019/01/qus-sports-introduces-washablesmart-fitness-shirt-and-bra/ (accessed on 27 June 2021).

119. Carey, T.; Cacovich, S.; Divitini, G.; Ren, J.; Mansouri, A.; Kim, J.M.; Wang, C.; Ducati, C.; Sordan, R.; Torrisi, F. Fully inkjet-printed two-dimensional material field-effect heterojunctions for wearable and textile electronics. Nat Commun. 2017, 8, 1202. [CrossRef] [PubMed]

120. Montazerian, H.; Rashidi, A.; Dalili, A.; Najjaran, H.; Milani, A.S.; Hoorfar, M. Graphene Coated Spandex Sensors Embedded into Silicone Sheath for Composites Health Monitoring and Wearable Applications. Small 2019, 15, 1804991. [CrossRef]

121. Fast Company, E-Textile. Available online: https://www.fastcompany.com/3046871/this-e-textile-could-replace-your-iphone (accessed on 29 March 2021).

122. Barakzehi, M.; Montazer, M.; Sharif, F.; Norby, T.; Chatzitakis, A. A textile-based wearable supercapacitor using reduced graphene oxide/polypyrrole composite. Electrochim. Acta 2019, 305, 187-196. [CrossRef]

123. Yang, Z.; Pang, Y.; Han, X.L.; Yang, Y.; Ling, J.; Jian, M.; Zhang, Y.; Yang, Y.; Ren, T.L. Graphene Textile Strain Sensor with Negative Resistance Variation for Human Motion Detection. ACS Nano 2018, 12, 9134-9141. [CrossRef] [PubMed]

124. Afroj, S.; Tan, S.; Abdelkader, A.M.; Novoselov, K.S.; Karim, N. Highly conductive, scalable, and machine washable graphenebased E-textiles for multifunctional wearable electronic applications. Adv. Funct. Mater. 2020, 30, 2000293. [CrossRef]

125. Yin, B.; Wen, Y.; Hong, T.; Xie, Z.; Yuan, G.; Ji, Q.; Jia, H. Highly stretchable, ultrasensitive, and wearable strain sensors based on facilely prepared reduced graphene oxide woven fabrics in an ethanol flame. ACS Appl. Mater. Interfaces 2017, 9, 32054-32064. [CrossRef] [PubMed]

126. Du, D.; Tang, Z.; Ouyang, J. Highly washable e-textile prepared by ultrasonic nano soldering of carbon nanotubes onto polymer fibers. J. Mater. Chem. C 2018, 6, 883-889. [CrossRef]

127. Cao, R.; Pu, X.; Du, X.; Yang, W.; Wang, J.; Guo, H.; Zhao, S.; Yuan, Z.; Zhang, C.; Li, C.; et al. Screen-Printed Washable Electronic Textiles as Self-Powered Touch/Gesture Tribo-Sensors for Intelligent Human-Machine Interaction. ACS Nano 2018, 12, 5190-5196. [CrossRef] [PubMed]

128. Amjadi, M.; Pichitpajongkit, A.; Lee, S.; Ryu, S.; Park, I. Highly stretchable and sensitive strain sensor based on silver nanowireelastomer nanocomposite. ACS Nano 2014, 8, 5154-5163. [CrossRef] [PubMed]

129. Amjadi, M.; Kyung, K.-U.; Park, I.; Sitti, M. Stretchable, skin-mountable, and wearable strain sensors and their potential applications: A review. Adv. Funct. Mater. 2016, 26, 1678-1698. [CrossRef]

130. Chossat, J.-B.; Park, Y.-L.; Wood, R.J.; Duchaine, V. A soft strain sensor based on ionic and metal liquids. IEEE Sens. J. 2013, 13, 3405-3414. [CrossRef]

131. Han, Y.L.; Liu, H.; Ouyang, C.; Lu, T.J.; Xu, F. Liquid on paper: Rapid prototyping of soft functional components for paper electronics. Sci. Rep. 2015, 5, 11488. [PubMed]

132. Eom, J.; Jaisutti, R.; Lee, H.; Lee, W.; Heo, J.S.; Lee, J.Y.; Park, S.K.; Kim, Y.H. Highly sensitive textile strain sensors and wireless user-interface devices using all-polymeric conducting fibers. ACS Appl. Mater. Interfaces 2017, 9, 10190-10197. [CrossRef] [PubMed]

133. Jia, H.; Wang, J.; Zhang, X.; Wang, Y. Pen-writing polypyrrole arrays on paper for versatile cheap sensors. ACS Macro Lettvol. 2014, 3, 86-90. [CrossRef]

134. Yoon, S.G.; Koo, H.J.; Chang, S.T. Highly stretchable and transparent microfluidic strain sensors for monitoring human body motions. ACS Appl. Mater. Interfaces 2015, 7, 27562-27570. [CrossRef] [PubMed]

135. McCann, J.; Bryson, D. Smart Clothes and Wearable Technology, 1st ed.; Woodhead Publishing: Cambridge, UK, 2009.

136. Hu, Y.; Zheng, Z. Progress in textile-based triboelectric nanogenerators for smart fabrics. Nano Energy 2019, 56, 16-24. [CrossRef] 
137. Qiu, Q.; Zhu, M.; Li, Z.; Qiu, K.; Liu, X.; Yu, J.; Ding, B. Highly flexible, breathable, tailorable and washable power generation fabrics for wearable electronics. Nano Energy 2019, 58, 750-758. [CrossRef]

138. Luheng, W.; Tianhuai, D.; Peng, W. Influence of carbon black concentration on piezoresistivity for carbon-black-filled silicone rubber composite. Carbon 2009, 47, 3151-3157. [CrossRef]

139. Tech Xplore, Washable Fabrics. Available online: https://techxplore.com/news/2018-08-incorporate-optoelectronic-diodesfibers-washable.html (accessed on 1 June 2021).

140. Kim, M.; Kim, H.; Park, J.; Jee, K.; Lim, J.; Park, M. Real-time sitting posture correction system based on highly durable and washable electronic textile pressure sensors. Sens. Actuators A Phys. 2018, 269, 394-400. [CrossRef]

141. Shimojo, M.; Namiki, A.; Ishikawa, M.; Makino, R.; Mabuchi, K. A tactile sensor sheet using pressure conductive rubber with electrical-wires stitched method. IEEE Sens. J. 2004, 4, 589-596. [CrossRef]

142. ETH, Woven Electronics. 2019. Available online: https://www.ethlife.ethz.ch/archive_articles/100701_smarte_textilien_per/ index_EN.html (accessed on 29 October 2020).

143. Abdelkader, A.M.; Karim, N.; Vallés, C.; Afroj, S.; Novoselov, K.S.; Yeates, S.G. Ultraflexible and Robust Graphene Supercapacitors Printed on Textiles for Wearable Electronics Applications. 2D Mater. 2017, 4, 035016. [CrossRef]

144. McKnight, M.; Agcayazi, T.; Ghosh, T.; Bozkurt, A. Chapter 8-Fiber-Based Sensors: Enabling Next-Generation Ubiquitous Textile Systems. In Wearable Technology in Medicine and Health Care; Academic Press: Cambridge, MA, USA, 2018 ; pp. $153-171$.

145. Lee, S.H.; Choi, M.H.; Han, S.H.; Choo, D.J.; Jang, J.; Kwon, S.K. High-performance thin-film transistor with 6,13bis(triisopropylsilylethynyl) pentacene by inkjet printing. Org. Electron. 2008, 9, 721-726. [CrossRef]

146. Brioude, M.D.M.; Guimarães, D.H.; Fiúza, R.D.P.; Prado, L.A.S.D.A.; Boaventura, J.S.; José, N.M. Synthesis and characterization of aliphatic polyesters from glycerol, by-product of biodiesel production, and adipic acid. Mater. Res. 2007, 10, 335-339. [CrossRef]

147. talk2myShirt. Koyono BlackCoat Work. 2006. Available online: http://www.talk2myshirt.com/blog/archives/12 (accessed on 12 May 2021).

148. Fernández-Caramés, T.M.; Fraga-Lamas, P.; Suárez-Albela, M.; Vilar-Montesinos, M. A Fog Computing and Cloudlet Based Augmented Reality System for the Industry 4.0 Shipyard. Sensors 2018, 18, 1798. [CrossRef]

149. Bove, L.A. Increasing Patient Engagement Through the Use of Wearable Technology. J. Nurse Pract. 2019, 15, 535-539. [CrossRef]

150. Carpi, F.; de Rossi, D. Electroactive polymer-based devices for e-textiles in biomedicine. IEEE Trans. Inf. Technol. Biomed. 2005, 9 , 295-318. [CrossRef]

151. Paul, G.; Torah, R.; Yang, K.; Beeby, S.; Tudor, J. An investigation into the durability of screen-printed conductive tracks on textiles. Meas. Sci. Technol. 2014, 25, 025006. [CrossRef]

152. Ching, K.W.; Singh, M.M. Wearable Technology Devices Security and Privacy Vulnerability Analysis. Int. J. Netw. Secur. Appl. (IJNSA) 2016, 8, 19-30. [CrossRef]

153. World Health Organization. ICT Facts and Figures. 2017. Available online: https://www.itu.int/en/ITU-D/Statistics/ Documents / facts /ICTFactsFigures2017.pdf (accessed on 19 December 2021).

154. Mokhtarian, P.L.; Tang, W. Trivariate probit models of pre-purchase/purchase shopping channel choice: Clothing purchases in Northern California. In Choice Modelling; Hess, S., Daly, A., Eds.; Institute of Transportation Studies, University of California Davis: Davis, CA, USA, 2013; pp. 243-273. 